\title{
The impact of observing characteristics on the ability to predict ozone under varying polluted photochemical regimes
}

\author{
P. D. Hamer ${ }^{1,2,3}$, K. W. Bowman ${ }^{1}$, D. K. Henze ${ }^{4}$, J.-L. Attié ${ }^{5}$, and V. Marécal ${ }^{2}$ \\ ${ }^{1}$ Jet Propulsion Laboratory, California Institute of Technology, Pasadena, California, USA \\ ${ }^{2}$ Centre National de Recherches Météorologiques - Groupe d'étude de l'Atmosphère Météorologique, Météo-France and \\ CNRS, UMR3589, Toulouse, France \\ ${ }^{3}$ NILU - Norwegian Institute for Air Research, Kjeller, Norway \\ ${ }^{4}$ Department of Mechanical Engineering, University of Colorado, Boulder, Colorado, USA \\ ${ }^{5}$ Laboratoire d'Aérologie, Université de Toulouse, CNRS, UMR, Toulouse, France \\ Correspondence to: P. D. Hamer (paul.d.hamer@gmail.com, paul.hamer@meteo.fr)
}

Received: 23 December 2014 - Published in Atmos. Chem. Phys. Discuss.: 23 February 2015

Revised: 29 July 2015 - Accepted: 25 August 2015 - Published: 25 September 2015

\begin{abstract}
We conduct analyses to assess how characteristics of observations of ozone and its precursors affect air quality forecasting and research. To carry out this investigation, we use a photochemical box model and its adjoint integrated with a Lagrangian 4D-variational data assimilation system. Using this framework in conjunction with pseudoobservations, we perform an ozone precursor source inversion and estimate surface emissions. We then assess the resulting improvement in ozone air quality prediction. We use an analytical model to conduct uncertainty analyses. Using this analytical tool, we address some key questions regarding how the characteristics of observations affect ozone precursor emission inversion and in turn ozone prediction. These questions include what the effect is of choosing which species to observe, of varying amounts of observation noise, of changing the observing frequency and the observation time during the diurnal cycle, and of how these different scenarios interact with different photochemical regimes. In our investigation we use three observed species scenarios: $\mathrm{CO}$ and $\mathrm{NO}_{2}$; ozone, $\mathrm{CO}$, and $\mathrm{NO}_{2}$; and $\mathrm{HCHO}, \mathrm{CO}$ and $\mathrm{NO}_{2}$. The photochemical model was set up to simulate a range of summertime polluted environments spanning $\mathrm{NO}_{x}$ ( $\mathrm{NO}$ and $\mathrm{NO}_{2}$ )-limited to volatile organic compound (VOC)limited conditions. We find that as the photochemical regime changes, here is a variation in the relative importance of trace gas observations to be able to constrain emission estimates and to improve the subsequent ozone forecasts. For example, adding ozone observations to an $\mathrm{NO}_{2}$ and $\mathrm{CO}$ observ-
\end{abstract}

ing system is found to decrease ozone prediction error under $\mathrm{NO}_{x}$ - and VOC-limited regimes, and complementing the $\mathrm{NO}_{2}$ and $\mathrm{CO}$ system with $\mathrm{HCHO}$ observations would improve ozone prediction in the transitional regime and under VOC-limited conditions. We found that scenarios observing ozone and $\mathrm{HCHO}$ with a relative observing noise of lower than $33 \%$ were able to achieve ozone prediction errors of lower than 5 ppbv (parts per billion by volume). Further, only observing intervals of $3 \mathrm{~h}$ or shorter were able to consistently achieve ozone prediction errors of 5 ppbv or lower across all photochemical regimes. Making observations closer to the prediction period and either in the morning or afternoon rush hour periods made greater improvements for ozone prediction: $0.2-0.3 \mathrm{ppbv}$ for the morning rush hour and from 0.3 to $0.8 \mathrm{ppbv}$ for the afternoon compared to only $0-0.1 \mathrm{ppbv}$ for other times of the day. Finally, we made two complementary analyses that show that our conclusions are insensitive to the assumed diurnal emission cycle and to the choice of which VOC species emission to estimate using our framework. These questions will address how different types of observing platform, e.g. geostationary satellites or ground monitoring networks, could support future air quality research and forecasting. 


\section{Introduction}

Ozone is a hazard to human health (Mustafa, 1990; Pryor, 1992; WHO, 2013) and plants and animals (Murphy et al., 1999; Fumagalli et al., 2001; Nali et al., 2002; Van Dingenen et al., 2009) and a greenhouse gas (IPCC, 2007). Prediction of ozone air quality on local and regional scales is key for providing prior warning of impending ozone exceedances (Dabberdt et al., 2004, 2006). Knowledge of the processes that control the variability in ozone precursors is vital for understanding and predicting ozone air quality.

Currently, a wide variety of techniques are used to predict ozone concentrations ranging from statistically based models (Gardner and Dorling, 2000) and neural networks (Yi and Prybutok, 1996) to prognostic models of atmospheric processes that include data assimilation (Grell et al., 2005; Otte et al., 2005; Zhang et al., 2008; Kang et al., 2010; Marécal et al., 2015). For prognostic models, uncertainties result from meteorology, the limitations of the photochemical mechanisms, wet and dry deposition, uncertainties in the emissions of ozone precursors, and, for data assimilation, observation uncertainty (Dabberdt et al., 2004, 2006). Most current statistical and data assimilation air quality forecasting techniques rely primarily on surface observing networks, but satellite observations are increasingly coming to the fore (Lahoz et al., 2012).

Ozone pollution can develop under different polluted photochemical regimes. Under low to moderate levels of $\mathrm{NO}_{x}$ ( $\mathrm{NO}$ and $\mathrm{NO}_{2}$ ) pollution, such as can be found in rural and suburban environments, increases in $\mathrm{NO}_{x}$ lead to proportional increases in ozone, which is why this regime is classed as $\mathrm{NO}_{x}$ limited (Trainer et al., 1987; Sillman, 1993; Jacob et al., 1993). Under much higher levels of $\mathrm{NO}_{x}$ pollution, i.e. those present in densely populated regions, increases in $\mathrm{NO}_{x}$ bring about decreases in ozone. Under these conditions, the only means by which ground-level ozone can increase are via increases in volatile organic compound (VOC) emissions (Finlayson-Pitts and Pitts, 1997), and consequently this regime is considered to be VOC limited. Further, studies show that the sensitivity of ozone to either $\mathrm{NO}_{x}$ or VOCs can vary with time, e.g. during different days of the week (Blanchard and Fairley, 2001; Blanchard and Tanenbaum, 2003). The priorities to monitor and observe ozone and its different precursors therefore vary according to location and time.

Observations and models, and their combination through data assimilation, comprise essential tools for air quality prediction (Zhang et al., 2008; Strunk et al., 2010; Zhang et al., 2012). Observations are an essential part of such systems, so it follows that their characteristics could directly affect their performance. We seek to address this connection in our study. Given this, we will now attempt to review the relevant characteristics of the current and planned (in the near term) state of the air quality monitoring network in order to explain the motivation for our work and, later, to place some of our findings in context.
The US national surface air quality observing network typically observes a wide range of chemical species. For instance, surface monitoring sites within California (http: //www.arb.ca.gov/adam/) have instruments that can measure in situ ozone, $\mathrm{CO}, \mathrm{NO}_{2}$, nitrogen oxide, particulate matter with diameters of 2.5 and $10 \mu \mathrm{m}$, sulfur dioxide $\left(\mathrm{SO}_{2}\right)$, methane, total hydrocarbons, and hydrogen sulfide. The surface network is also usually able to make observations at least at an hourly temporal resolution. However, due to the spatial limitations of the surface air quality monitoring network, space-borne remote-sensing observations, which typically have greater spatial sampling, are also able to support air quality research and operational air quality forecasting (Lahoz et al., 2012).

Surface station in situ data are made at a high spatial resolution (a few metres up to a tens of kilometres), which is typically much higher than most air quality models. As a result, this introduces the problem of having representativity errors between the model, which is unable to represent fine-scale variability, and the observations that can measure this variability. This problem therefore limits the efficacy of data assimilation and systems need to be carefully designed to take this type of error into account.

For this study, the spatial characteristics of observations from different platforms are not considered, but the advantages satellite data offer in terms of increased spatial coverage have been recognised. Consequently, various studies have been conducted that highlight the benefits of satelliteborne instruments for air quality research (Arellano et al., 2006; Konovalov et al., 2006; Martin, 2008; Millet et al., 2008; Jones et al., 2009; Bowman et al., 2009; Kurokawa et al., 2009; Dufour et al., 2010; Duncan et al., 2010; Kopacz et al., 2010; Fishman et al., 2010). Further, satellite observations of air pollutants have been used within data assimilation models to advance air quality research (Sandu et al., 2003a; Chai et al., 2007; Pierce et al., 2007; Zhang et al., 2008; Parrington et al., 2009).

Excluding the issue of spatial sampling, there are considerable differences between remote-sensing observations and the existing surface observing network. Each individual ground station is able to observe a wider range of species at the surface (see above) but only at a single point. On the other hand, space-based remote-sensing techniques can only observe a limited number of species that have relevance to air quality (such as ozone, $\mathrm{CO}, \mathrm{NO}_{2}, \mathrm{SO}_{2}, \mathrm{CH}_{4}$, glyoxal, and $\mathrm{HCHO}$ ), have coarser horizontal spatial resolution observing with a footprint ranging from several to up to tens of kilometres, and have (with current capabilities) only limited vertical resolution and sensitivity to the surface or boundary layer. Also, all of the studies cited above used instruments onboard satellites in low earth orbit (LEO). Due to the orbital configuration, LEO-borne instruments are only able to observe the same location on a far more infrequent basis compared to the temporal sampling of the ground-based network. 
Instruments onboard geostationary (GEO) satellites can also offer good spatial coverage (on the continental and regional scale) without sacrificing temporal sampling. This makes them potentially ideal to support future air quality research and forecasting. However, in order to achieve this goal, developments must be made to improve satellite instrument sensitivity to the boundary layer and surface gas phase composition (Lahoz et al., 2012). Various strategies have been proposed to achieve this aim (primarily for $\mathrm{CO}$ and ozone). They typically consist of either combining wavelength bands that have been previously exploited, i.e. ultraviolet (UV), visible (VIS), and IR (infrared) (Landgraf and Hasekamp, 2007; Worden et al., 2007, 2010; Fu et al., 2013; Cuesta et al., 2013), or by focusing on new wavelength bands, i.e. the Chappuis bands for ozone in the visible range (Zoogman et al., 2011) that offer potential novel benefits. The UV and the Chappuis band in the visible range were combined theoretically to determine the benefit of such an approach during the development of the TEMPO instrument (Zoogman et al., 2014) and as part of a European initiative (Hache et al., 2014).

As a result of the perceived benefits, several GEO missions are currently in the various stages of planning. These include the Geostationary Coastal and Air Pollution Events (GEO-CAPE) planned by NASA to cover the North American continent (http://science.nasa.gov/ earth-science/decadal-surveys/). Sentinel 4 (http://www.esa. int/esaLP/SEM3ZT4KXMF_LPgmes_0.html) is planned by ESA to cover Europe, and the Geostationary Environment Spectrometer (GEMS) (Lee et al., 2009) is aimed at providing coverage of East Asia. Further, NASA's decadal survey and Lee et al. (2009) state that GEO-CAPE and GEMS will observe the following trace gases: ozone, $\mathrm{CO}$ (not with GEMS), $\mathrm{NO}_{2}, \mathrm{HCHO}$, and $\mathrm{SO}_{2}$.

GEO-based observations of trace gases are therefore becoming more relevant for the study of air quality and for operational air quality forecasting. For the planned GEO missions, various choices exist regarding which wavelength bands to observe in, and these will influence the already limited range of observable species in the troposphere. In addition, instrument design choices affect how often observations can be made, at what time of day, and how well. For instance, thermal infrared (TIR)-based instruments cannot measure $\mathrm{NO}_{2}$, and UV-VIS instruments cannot observe during the night-time. Thus, instrument design choices will affect the future capabilities of these missions.

We have demonstrated that a range of possible capabilities and characteristics exist for both the current and planned air quality observing systems (ground and satellite based). Within the scope of this paper, we study how the frequency and specific timing during the day of observation, the species that are measured, and how well they are measured affect the ability to conduct air quality research and to aid air quality forecasting using a data assimilation system. This interaction between observation characteristics and data assimila- tion system performance is interesting and needs to be studied. Therefore, addressing this question will be of interest to the current air quality observing network and to the planned or future GEO air quality focused missions. In order to do this, we carry out a series of sensitivity analyses using different sets of pseudo-observations to test the influence that various observation characteristics have upon the ability to predict ozone within an idealised model. This model consists of a photochemical box model, its adjoint, and a 4Dvariational data assimilation system set-up to constrain ozone precursor emission uncertainties $\left(\mathrm{NO}_{x}, \mathrm{CO}\right.$, and VOCs). This framework thereby mimics a state of the art air quality forecasting system. We conduct an uncertainty analysis using a linear estimation technique for each of our sensitivity tests. We are able to perform the uncertainty analysis owing to the fact that we use a box model because it limits the size of the matrices we solve for. Within the context of a summertime ozone pollution episode that emerges during stagnant anticyclonic conditions, we attempt to address the following specific questions:

- How does the ability to predict ozone vary across three separate observing scenarios? The first uses only $\mathrm{CO}$ and $\mathrm{NO}_{2}$ observations $(\mathrm{CN})$, the second uses Ozone, $\mathrm{CO}$, and $\mathrm{NO}_{2}(\mathrm{OCN})$, and the third uses $\mathrm{HCHO}, \mathrm{CO}$, and $\mathrm{NO}_{2}(\mathrm{HCN})$.

- What are the effects of both observing frequency and the choice of when to observe on the prediction of ozone within our framework?

- How does observation noise, when applied evenly onto each observation, affect ozone prediction in our system?

- How are the results of these sensitivity tests affected by photochemical regime (i.e., either $\mathrm{NO}_{x}$ - or VOClimited regimes)?

- Ignoring ozone prediction, which combination of observed species allows the best constraint on ozone precursor emissions?

In order to support our conclusions regarding the aims above we carry out a variety of complementary analyses

- to demonstrate that the 4D-variational data assimilation scheme can solve the full non-linear retrieval of the emission parameters;

- to test the robustness of our methodology to choices regarding our assumed diurnal emission profile;

- to test whether the assumed VOC emission uncertainties can be represented using different VOCs.

Section 2 describes all aspects of the methodology, Sect. 3 describes the results from each of the analyses, Sect. 4 discusses our results, Sect. 5 details our conclusions. 


\section{Methodology}

\subsection{Overview}

We use a photochemical box model run over 3 days to represent a worsening period of ozone air quality during a stagnation event. Meteorological stagnation events under hot, sunlit conditions over urban areas typically lead to poor ozone air quality (Jacob et al., 1993; Valente et al., 1998). We assume that the idealised mixing and transport represented in the box model are sufficient to represent the meteorology during anticyclonic conditions. For each of the different sensitivity tests that we perform we use different sets of pseudo-observations of ozone, $\mathrm{HCHO}, \mathrm{CO}$ and $\mathrm{NO}_{2}$ (see Sect. 2.3 and examine Fig. 3 to see an example of the pseudo-observations relative to the true ozone state) in order to separately constrain the ozone precursor emissions with the 4D-variational data assimilation system. The ozone precursor emissions have known a priori errors. We then make a prediction of ozone using the a posteriori emissions. Within the model framework, days 1-2 represent the period over which observations are made and the assimilation is carried out and the final day represents the prediction and monitoring period. Within this final phase, we compare the ozone prediction, based upon the a posteriori emissions, to the ozone true state in order to assess the assimilation performance. We support this assessment using a range of statistics and diagnostics that shall be discussed shortly.

The use of 4D-variational data assimilation to solve the ozone precursor emission inversion problem is consistent with the current state of the art in prognostic air quality forecast modelling development. For example, the Community Multi Scale Air Quality modelling system (Hakami et al., 2007), the Sulfur Transport Eulerian Model (Zhang et al., 2008), and Elbern et al. (2007) are all developing such assimilation capabilities. Thus, our model framework is relevant to and is reflective of the current and future direction of air quality forecasting.

In order to establish the utility of more complex air quality forecasting systems that might use 4D-variational data assimilation, our prototype forecasting system is demonstrated theoretically. Since the emission inversion problem that we explore only becomes more complex as the model state space increases and additional sources of uncertainty are introduced, a failure to show sufficiently reduced prediction error in this simplified setting would indicate that more complex systems are unlikely to fare better. Sufficient prediction model error within our framework is therefore a necessary but not sufficient condition for more complex 4D-variational data assimilation forecasting systems using air quality observations to be successful.

One other advantage of selecting a photochemical box model is that we are able to generate a Jacobian describing the model response to emission parameter perturbations, which can be used within an analytical modelling framework to conduct uncertainty analysis. It would be very difficult to produce a Jacobian within regional or global chemical transport models in a timely fashion given the size of the model state space. Therefore, we use an analytic model (derived from the photochemical box model) that is simplified relative to the full assimilation framework. This is a linear estimation technique based upon Rodgers (2000). To support our analyses we calculate the following diagnostics using this method: a posteriori ozone prediction error covariance, a posteriori emission parameter error covariance, the emission averaging kernel, and the associated degrees of freedom of signal.

The 4D-variational (4D-var) data assimilation and uncertainty analysis using the linear estimation are therefore complementary methods, and we use both techniques to achieve our aim of exploring the effect of observing characteristics on ozone prediction. In addition, we conduct a series of supporting analyses to test some of our assumptions.

\subsection{Photochemical box model}

A pseudo 1-D photochemical box model was built using the Kinetic Pre-Processor (KPP) (Damian et al., 2002; Daescu et al., 2003; Sandu et al., 2003b). The model is not truly 1$\mathrm{D}$ in the vertical because we use a parameterisation to describe variability in the boundary layer height and mixing volume. The Rosenbrock solver is used to integrate the KPPgenerated ordinary differential equations required to calculate trace gas concentrations (Eller et al., 2009). The photochemical mechanism consists of 171 gas phase species and 524 chemical reactions simulating the degradation of hydrocarbons from $\mathrm{C}_{1}$ to $\mathrm{C}_{5}$ including isoprene and is based upon the Master Chemical Mechanism v3.1 (Jenkin et al., 1997) (http://mcm.leeds.ac.uk/MCM/). In addition, the model includes dry deposition for all relevant chemical species, it contains a two-parameter photolysis scheme, and it simulates the emission of ozone precursors including $\mathrm{NO}_{x}, \mathrm{CO}$, and VOCs.

Coastal urbanised southern California (SC) has historically been, and continues to be, an interesting area of study for air quality owing to the large-scale urbanisation and population, the resulting anthropogenic emissions, and the meteorological conditions during summertime that are favourable for the development of photochemical smog conditions. We therefore set up the box model to study conditions that are analogous to this region and environment. Consequently, we situate the box model at $33^{\circ} \mathrm{N}$, run it from 30 June to 2 July, and use an atmospheric humidity equivalent to a volume mixing ratio of 0.0162. In addition, we use anthropogenic $\left(\mathrm{NO}_{x}\right.$, $\mathrm{CO}$, and VOCs) and biogenic (isoprene) emissions that result in a range of atmospheric mixing ratios typical for urbanised SC.

The diurnal emission variability in anthropogenic compounds is prescribed according to the National Atmospheric Emissions Inventory (NAEI) (http://www.naei.org.uk/emissions/) for an urbanised 


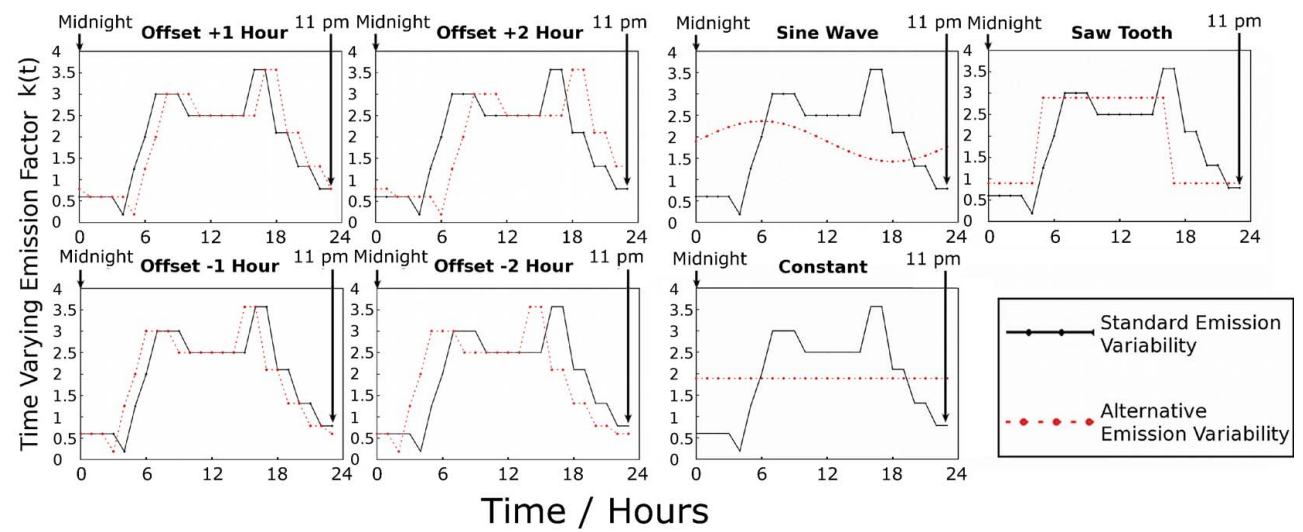

Figure 1. The various different profiles of the temporal variability emission factor, $k(t)$, used in the analysis of the emission solution sensitivity to diurnal emission variability. The red dashed and the solid black lines indicate the alternative and standard emissions variabilities, respectively. The different profiles of variability are indicated at the top of each panel in bold text.

area (see Fig. 1), and the isoprene emission variability is parameterised to correlate to solar zenith angle offset by $2 \mathrm{~h}$ to consider both temperature and photon flux effects (Tingey et al., 1979; Tawfik et al., 2012). The isoprene emissions have an average daily emission of $1.7 \times 10^{10}$ molecules $\mathrm{m}^{2} \mathrm{~s}^{-1}$ and an afternoon peak of $4.6 \times 10^{10}$ molecules $\mathrm{m}^{2} \mathrm{~s}^{-1}$, which yields modelled isoprene mixing ratios less than $10 \mathrm{pptv}$ (parts per trillion by volume) typical for this region. The diurnal variability in the isoprene emissions is separate and distinct to the anthropogenic VOCs. From now on, when we discuss VOCs we are referring to anthropogenic VOCs unless otherwise stated. The VOC speciation is defined according to NAEI and the total peak emission of carbon via VOCs (excluding isoprene) is $2.3 \times 10^{12}$ carbon atoms $\mathrm{m}^{-2} \mathrm{~s}^{-1}$ and the average emission is $1.2 \times 10^{12}$ carbon atoms $\mathrm{m}^{-2} \mathrm{~s}^{-1}$. These anthropogenic VOC emissions are typical for urbanised regions. Boundary layer dynamics are described with a prescribed variability in mixing height ranging from 500 to $1500 \mathrm{~m}$ and mixing between the boundary layer and free troposphere equivalent to a constant $10 \%$ mass exchange per hour. In our model, the vertical extent represents the full depth of the boundary layer. Background free tropospheric concentrations of long-lived species are assumed to remain constant and are defined in Table 1.

The model is run under a range of photochemical conditions typical for urbanised SC. This is achieved by varying the NO emissions across nine different scenarios that span the full range of modelled ozone responses with respect to changing $\mathrm{NO}_{x}$ concentration (i.e. from $\mathrm{NO}_{x}$ - to VOC-limited conditions). We use the same emissions for the other species across all of these different NO emission scenarios. For the purposes of the emission inversion, we define our ozone precursor emissions in a simplified form (excluding emitted species not considered in the inversion) as
Table 1. Background free-tropospheric concentrations of trace gases mixed into the boundary layer in the photochemical model. NMHCs indicate non-methane hydrocarbons.

\begin{tabular}{ll}
\hline Chemical species & Background mixing ratio \\
\hline Ozone & $30 \mathrm{ppbv}$ \\
$\mathrm{NO}$ & $100 \mathrm{pptv}$ \\
$\mathrm{NO}_{2}$ & $50 \mathrm{pptv}$ \\
$\mathrm{CO}$ & $80 \mathrm{ppbv}$ \\
$\mathrm{CH}_{4}$ & $1.76 \mathrm{ppm}$ \\
$\mathrm{NMHCs}$ & $100-200 \mathrm{pptv}$ each \\
\hline
\end{tabular}

$\phi_{i}(t)=x_{i} E_{i}(t), i=\mathrm{NO}, \mathrm{CO}, \mathrm{VOC}$,

where $x_{i}$ represents the time-independent emission scaling factors for the emitted species, $i$, and $E_{i}(t)$ represents the emissions with a prescribed and repeating diurnal cycle for each emitted species. The emission inversion solves for $x_{i}$, the time-independent emission scaling factors, which can be represented as a vector, $\boldsymbol{x}$, for the emitted species, $i$, as shown by

$[x]_{i}=x_{i}, i=\mathrm{NO}, \mathrm{CO}, \mathrm{VOC}$.

Further, we define the true state of the emission scaling factors as $\boldsymbol{x t}$. The variability in $E_{\mathrm{NO}}(t)$ is shown in Fig. 2, and this variability is represented by

$E_{i}(t)=e_{i} k(t)$,

where $k(t)$ is the temporal variability emission factor for all of the emitted species and $e_{i}$ is the time-independent emission for each species. Note then that all of the anthropogenic emissions (NO, CO, and VOCs $\left.-E_{i}(t)\right)$ share the same temporal variability. The variability in $k(t)$ is shown in Fig. 1 as 
Table 2. Values of the different parameters and emissions used in the photochemical box model. The emissions are shown with the corresponding units of molecules $\mathrm{m}^{-2} \mathrm{~s}^{-1}$. Since $\overline{k(t)}$ is 1.89 , the average emissions, $\overline{E(t)}$, are a factor of 1.89 larger than $e_{i}$. For $\overline{E(t)}_{\mathrm{NO}}$, the value shown outside the brackets is equivalent to $x_{\mathrm{NO}}=1$, and the values in the brackets (same units) denote the range in the emissions that arise from using the full range of $x_{\mathrm{NO}}$ $(0.5-2.5)$.

\begin{tabular}{ll}
\hline $\begin{array}{l}\text { Model } \\
\text { variable }\end{array}$ & Parameter or emission value \\
\hline$\overline{k(t)}$ & 1.89 \\
$x_{\mathrm{NO}}$ & $0.5,0.75,1.0,1.25,1.5,1.75,2.0,2.25,2.5$ \\
$e_{\mathrm{NO}}$ & $4.8 \times 10^{10}$ molecules $\mathrm{m}^{-2} \mathrm{~s}^{-1}$ \\
$e_{\mathrm{CO}}$ & $2.6 \times 10^{12}$ molecules $\mathrm{m}^{-2} \mathrm{~s}^{-1}$ \\
$e_{\mathrm{VOC}}$ & $4.3 \times 10^{10}$ molecules $^{-2} \mathrm{~s}^{-1}$ \\
$\overline{E(t)}_{\mathrm{NO}}$ & $9 \times 10^{10}$ molecules $^{-2} \mathrm{~s}^{-1}\left(4.5 \times 10^{10}-2.3 \times 10^{11}\right)$ \\
$\overline{E(t)}_{\mathrm{CO}}$ & $5 \times 10^{12}$ molecules $\mathrm{m}^{-2} \mathrm{~s}^{-1}$ \\
$\overline{E(t)}_{\mathrm{VOC}}$ & $8.2 \times 10^{10}$ molecules $^{-2} \mathrm{~s}^{-1}$ \\
\hline
\end{tabular}

Table 3. Simulated range in peak $\mathrm{NO}_{x}$ mixing ratios that result from the different photochemical scenarios using different $x_{\mathrm{NO}}(0.5-2.5)$. Also shown are the ranges of peak $\mathrm{CO}$ and $\mathrm{HCHO}$ that result from emissions of $\mathrm{CO}$ and VOCs, respectively.

\begin{tabular}{ll}
\hline Chemical species & Modelled peak mixing ratio range \\
\hline $\mathrm{NO}_{x}$ & $4.0-24.0 \mathrm{ppbv}$ \\
$\mathrm{NO}$ & $1-11.3 \mathrm{ppbv}$ \\
$\mathrm{NO}_{2}$ & $3-16.9 \mathrm{ppbv}$ \\
$\mathrm{CO}$ & $590-820 \mathrm{ppbv}$ \\
$\mathrm{HCHO}$ & $6.5-8.1 \mathrm{ppbv}$ \\
\hline
\end{tabular}

the "standard emission variability". Table 2 shows the values of $e_{\mathrm{NO}}, e_{\mathrm{CO}}$, and $e_{\mathrm{VOC}}$ used in our model simulations.

In the emission inversion calculations, we represent VOC emissions via ethene emissions. We selected ethene because it is a sufficiently reactive gas that is emitted in abundance through the course of anthropogenic activity. Thus, the adjoint sensitivities to ethene emissions are sufficiently high to allow the 4D-var system to find adequate solutions for the VOC emission parameter. Table 2 describes the set-up of the photochemical model for the range of different NO emission scenarios that we investigate and shows the values of $\overline{k(t)}$, and, for each species, $e$ and $\overline{E(t)}$. Note that for $\overline{E(t)}$ the overbar indicates the mean value of a variable.

The NO emission scalings shown in Table 2 are chosen to represent a wide range of photochemical conditions and given the VOC burden in the model, $x_{\mathrm{NO}}$ emission scalings $0.5,0.75$ and 1.0 represent $\mathrm{NO}_{x}$-limited conditions, $1.25,1.5$ and 1.75 represent transitional conditions, and 2.0,2.25, and 2.5 represent VOC-limited conditions. The mixing ratios of $\mathrm{NO}_{x}$ that result from these different NO emission factors, and the mixing ratios of $\mathrm{CO}$ and $\mathrm{HCHO}$ that result from the $\mathrm{CO}$ and VOC emissions are all summarised in Table 3.
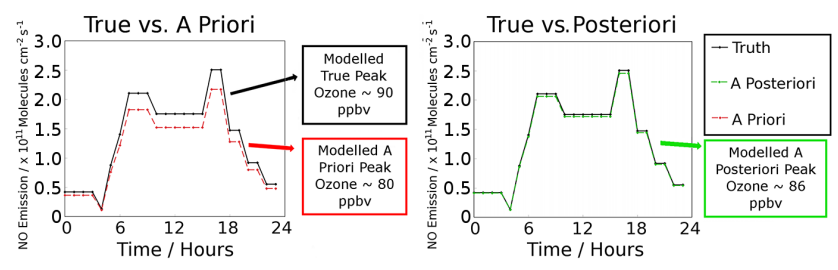

Figure 2. A schematic showing how both the a priori and a posteriori emissions relate to the true emissions of NO and the modelled peak afternoon ozone that results from these emission variabilities. Note that the same emission variability is used for all of the anthropogenic chemical species emitted in the model. The a priori and a posteriori emissions are scaled relative to the true emissions, and these differences can be characterised as being due to different emission scaling factors (i.e. $x_{\mathrm{NO}}$ ) for the a priori, a posteriori and true emissions. The solid black, green dashed and red dashed lines show the truth, a posteriori, and a priori emissions, respectively.

\subsection{Forecasting framework and 4D-variational data assimilation}

Several $\mathrm{NO}_{x}$ emissions scenarios are simulated to cover a wide range of photochemical conditions $\left(x_{\mathrm{NO}}=0.5-2.5\right)$. Each emission scenario is represented mathematically as a forward model, $\mathbf{F}(\boldsymbol{x}, t)$, which represents the concentrations as a function of time-evaluated emissions, $\boldsymbol{x}$. Depending on the scenario, either pseudo-observations of $\mathrm{CO}, \mathrm{NO}_{2}, \mathrm{O}_{3}$, or $\mathrm{HCHO}$ are used in various combinations (see Fig. 3 for a representation of the ozone pseudo-observations relative to the true state for ozone). In order to derive the pseudoobservations the model true state is sampled at 3-hourly intervals in the standard scenarios (used as default unless specified) and at intervals between 1 and $24 \mathrm{~h}$ in scenarios characterising the impact of observing frequency on prediction error. The sampled species concentrations are then combined with an additive-noise model to generate the pseudoobservations, $\boldsymbol{y}$, represented by

$\boldsymbol{y}=\mathbf{F}(\boldsymbol{x}, t)+\boldsymbol{n}$,

where $\boldsymbol{n}$ is the noise

$\boldsymbol{n}=\overline{\mathbf{F}(\boldsymbol{x})} \times \beta \times \epsilon$,

where $\overline{\mathbf{F}(\boldsymbol{x})}$ is the average species concentration (values shown in Table 4), $\beta$ is the noise scaling factor, and $\epsilon$ is a random number with a normalised Gaussian distribution with a standard deviation of 1 and a mean of 0 . The modelled concentrations for all species and times resulting from $\mathbf{F}(x)$ can be represented as a vector, $\boldsymbol{q}$,

$q=\mathbf{F}(\boldsymbol{x}, t)$

or for specific species, $z$, at time $t$ as $q_{z}(\boldsymbol{x}, t)$,

$\boldsymbol{q}_{z}(\boldsymbol{x}, t)=[\mathbf{F}(\boldsymbol{x}, t)]_{z}$, 
Table 4. Values of $\overline{\mathbf{F}(\boldsymbol{x})}$ used to calculate $\boldsymbol{y}$. The overbar indicates that this represents the mean value.

\begin{tabular}{ll}
\hline $\mathbf{F}(\hat{\boldsymbol{x}})$ & Mixing ratio \\
\hline Ozone & $44.4 \mathrm{ppbv}$ \\
$\mathrm{CO}$ & $620 \mathrm{ppbv}$ \\
$\mathrm{NO}_{2}$ & $6.5 \mathrm{ppbv}$ \\
$\mathrm{HCHO}$ & $3.9 \mathrm{ppbv}$ \\
\hline
\end{tabular}

Table 5. Values of $\boldsymbol{x}$ and $\boldsymbol{x}_{\mathrm{a}}$ (in terms of unitless emission scaling factor) used in the 4D-variational data assimilation model.

\begin{tabular}{rrrrrrr}
\hline \multicolumn{3}{c}{$\boldsymbol{x}$} & & & \multicolumn{3}{c}{$\boldsymbol{x}_{\mathrm{a}}$} \\
\cline { 1 - 3 } \cline { 6 - 7 } NO & CO & VOC & & NO & CO & VOC \\
\hline 0.5 & 1.0 & 6.5 & & 0.475 & 0.95 & 0.1 \\
0.75 & - & - & & 0.7125 & - & - \\
1.0 & - & - & 0.95 & - & - \\
1.25 & - & - & & 1.1875 & - & - \\
1.5 & - & - & & 1.425 & - & - \\
1.75 & - & - & 1.8375 & - & - \\
2.0 & - & - & & 2.1 & - & - \\
2.25 & - & - & 2.3625 & - & - \\
2.5 & - & - & 2.625 & - & - \\
\hline
\end{tabular}

where $z$ can be $\mathrm{O}_{3}, \mathrm{NO}_{2}, \mathrm{CO}$ or $\mathrm{HCHO}$. We define a priori emission scaling factors, $\boldsymbol{x}_{\mathrm{a}}$, with specified errors relative to $\boldsymbol{x} \boldsymbol{t}$ (Table 5 provides a summary of the values of $x$ used for both $\boldsymbol{x} \boldsymbol{t}$ and $\boldsymbol{x}_{\mathrm{a}}$ ), which are combined with the model to yield the a priori model state, $\mathbf{F}\left(\boldsymbol{x}_{\mathrm{a}}\right)$. Note that within our framework the a priori is also the initial guess.

The assimilation is started at the first iteration with the forward model using the initial guess and is thus described as $\mathbf{F}\left(\boldsymbol{x}_{\mathrm{a}}\right)$ after one iteration. A cost function, which is a scalar, $J(\boldsymbol{x})$, is then evaluated:

$$
\begin{aligned}
J(\boldsymbol{x}) & =\frac{1}{2}\left((\boldsymbol{y}-\mathbf{F}(\boldsymbol{x}))^{\mathrm{T}} \mathbf{S}_{\mathrm{n}}^{-1}(\boldsymbol{y}-\mathbf{F}(\boldsymbol{x}))\right. \\
& \left.+\frac{1}{2}\left(\boldsymbol{x}-\boldsymbol{x}_{\mathrm{a}}\right)^{\mathrm{T}} \mathbf{S}_{\mathrm{a}}^{-1}\left(\boldsymbol{x}-\boldsymbol{x}_{\mathrm{a}}\right)\right),
\end{aligned}
$$

where $\mathbf{S}_{\mathrm{a}}$ is the a priori constraint matrix and $\mathbf{S}_{\mathrm{n}}$ is the observation error covariance (where the superscript $T$ indicates the transpose). The 4D-variational data assimilation method seeks the solution for $\boldsymbol{x}, \hat{\boldsymbol{x}}$, that minimises $J(\boldsymbol{x})$,

$\hat{\boldsymbol{x}}=\min _{x} J(\boldsymbol{x})$,

such that the gradient of the cost function with respect to $x$ is 0 if the solution $\hat{\boldsymbol{x}}$ is equal to the true state, $\boldsymbol{x} \boldsymbol{t}$, (though this is never fully achieved):

$\nabla_{x} J=\mathbf{K}^{\mathrm{T}} \mathbf{S}_{\mathrm{n}}^{-1}(\boldsymbol{y}-\mathbf{F}(\hat{\boldsymbol{x}}))-\mathbf{S}_{\mathrm{a}}^{-1}\left(\hat{\boldsymbol{x}}-\boldsymbol{x}_{\mathrm{a}}\right)=0$,

where $\mathbf{K}$ is the Jacobian matrix (see Eq. 15) describing the forward-model response to perturbations to the emission parameters and $\nabla_{x} J$ is the adjoint sensitivity (Daescu et al.,

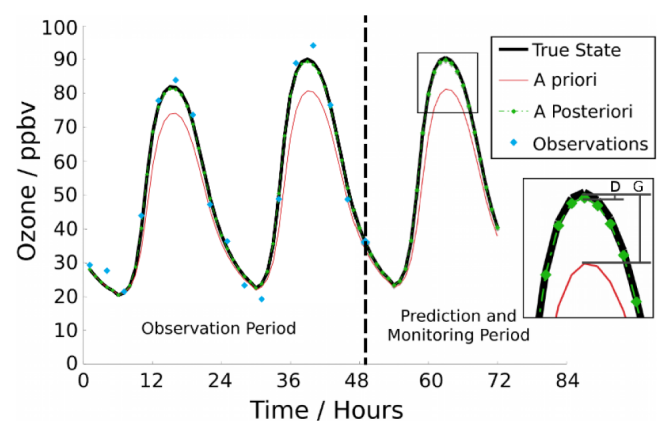

Figure 3. A representation of the ozone prototype forecasting framework and the 4D-variational data assimilation results for scenario $\mathrm{OCN}$ with $\beta=0.1$. The observation period covers the first $48 \mathrm{~h}$ period of the assimilation, during which time pseudoobservations are made (at a frequency of every $3 \mathrm{~h}$ in this case) and are used within the assimilation. The observations are used to constrain the emissions of ozone precursors, which in turn allows the forecasting model to produce the a posteriori ozone prediction. During the prediction and monitoring period the model true state now plays the monitoring role allowing comparisons to be made to the ozone forecast. The a posteriori ozone prediction represents the forecast for ozone concentrations 1 day in the future. $D$ represents the a posteriori prediction model error and $G$ represents the a priori and initial-guess prediction error. The black solid line, red solid line, green dashed line, and blue diamonds represent the truth, a priori, a posteriori, and pseudo-observations, respectively.

2003; Sandu et al., 2003b), which was calculated by the Rosenbrock solver (Eller et al., 2009) and which indicates the sensitivity of the cost function to the emission parameters. The cost function and its adjoint sensitivities are passed to the quasi-Newton L-BFGS algorithm (Zhu et al., 1997). The L-BFGS algorithm iteratively determines the optimal state of $\boldsymbol{x}, \hat{\boldsymbol{x}}$, that minimises the difference between the model and observations subject to the a priori constraints.

Using the estimated emissions, $\hat{\boldsymbol{x}}$, the forward model, $\mathbf{F}(\hat{\boldsymbol{x}})$, provides the air quality prediction of the ozone concentration, $q_{\mathrm{O}_{3}}(\boldsymbol{x}, t)$, on the afternoon of the third day of the simulation during the prediction and monitoring period. The relevance of $q_{\mathrm{O}_{3}}(\boldsymbol{x}, t)$ to the prediction and monitoring period is shown in Fig. 3.

Figure 2 shows how the a priori emissions, $\boldsymbol{x}_{\mathrm{a}}$, relate to the true emissions $\boldsymbol{x} \boldsymbol{t}$ and the a posteriori emissions, $\hat{\boldsymbol{x}}$, after the $4 \mathrm{D}$-variational data assimilation, as well as the a priori, the true and the a posteriori ozone levels (i.e. $q_{\mathrm{O}_{3}}\left(\boldsymbol{x}_{\mathrm{a}}, t\right)$, $q_{\mathrm{O}_{3}}(\boldsymbol{x} \boldsymbol{t}, t)$, and $q_{\mathrm{O}_{3}}(\hat{\boldsymbol{x}}, t)$, respectively). The left panel of Fig. 2 shows the a priori emission error for $\mathrm{NO}$ emissions and the right panel shows the a posteriori $\mathrm{NO}$ emission error. The a posteriori emission parameter error can be defined more generally as a vector $\tilde{\boldsymbol{x}}$. 
$\widetilde{\boldsymbol{x}}=\hat{\boldsymbol{x}}-\boldsymbol{x t}$

Figure 3 provides an example representation of the pseudoobservation ozone prediction, $q_{\mathrm{O}_{3}}(\hat{\boldsymbol{x}}, t)$, relative to the true state, $q_{\mathrm{O}_{3}}(\boldsymbol{x} t, t)$, during the prediction and monitoring period on the third day. In Fig. $3 \mathrm{D}$ represents the a posteriori ozone prediction error at time $t^{\mu}\left(t^{\mu}\right.$ is 15:00 LT on day 3 during the prediction and monitoring period), defined by

$D=q_{\mathrm{O}_{3}}\left(\hat{\boldsymbol{x}}, t^{\mu}\right)-q_{\mathrm{O}_{3}}\left(\boldsymbol{x} \boldsymbol{t}, t^{\mu}\right)$.

In Fig. $3 G$ represents the a priori ozone prediction error defined by

$G=q_{\mathrm{O}_{3}}\left(\boldsymbol{x}_{\mathrm{a}}, t^{\mu}\right)-q_{\mathrm{O}_{3}}\left(\boldsymbol{x t}, t^{\mu}\right)$.

The air quality prediction error over the entire prediction and monitoring period for each of the species, $z$, can be defined as a vector, $\widetilde{\boldsymbol{q}}$ :

$\left[\widetilde{\boldsymbol{q}}_{z}\right]_{j}=q_{z}\left(\hat{\boldsymbol{x}}, t_{j}\right)-q_{z}\left(\boldsymbol{x t}, t_{j}\right), j=3,6 \ldots 21,24$,

where $j$ is the hour of day on the third day during the prediction and monitoring period.

\subsection{Uncertainty analysis}

\subsubsection{Overview}

The uncertainty analysis has two foci: the evaluation of the performance of the emissions estimates and an estimation of the a posteriori ozone prediction error. Note that there is a direct synergy between these two analyses since uncertainties in the emissions estimate directly impact upon ozone prediction uncertainty. The diagnostics that we calculate in the analysis of the emissions uncertainties include the a posteriori emission parameter error, the emission averaging kernel matrix, and the emission inversion degrees of freedom of signal.

\subsubsection{The Jacobian matrix}

The Jacobian matrix can be used to help characterise the variance in $\widetilde{\boldsymbol{x}}$ and $\tilde{\boldsymbol{q}}$. Therefore, it is advantageous to determine $\mathbf{K}$. Within our framework, each element of $\mathbf{K}$ represents the forward-model response, $\partial q_{z}(\boldsymbol{x}, t) / \partial x_{i}$, at time $t$ and for observed species, $z$, to perturbations in emissions of species, $i$, in the case of the OCN scenario (using pseudo-observations of ozone, $\mathrm{CO}$, and $\mathrm{NO}_{2}$ ). It is defined by

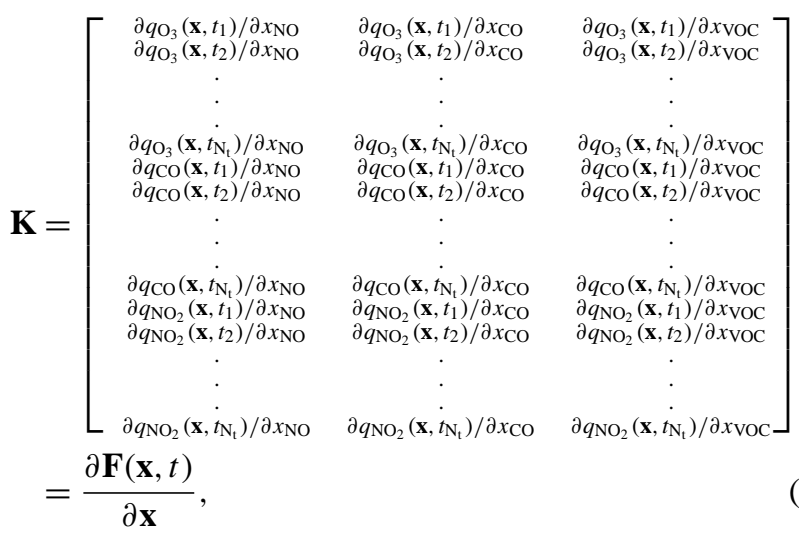

where $\mathbf{K}$ has dimensions $N_{i} \times N . N_{i}$ is the number of species in the emission factor state vector, $\boldsymbol{x}$, and is thus always 3 . We define $N$ as the total number of observations for all species:

$N=N_{t} \times N_{y}$,

where $N_{t}$ is the number of points in time at which the model perturbations are sampled and $N_{y}$ is the number of species whose perturbations are used in the Jacobian. In the case of Eq. (15) $y=\mathrm{O}_{3}, \mathrm{CO}$ and $\mathrm{NO}_{2}$; therefore, $N_{y}=3$. $\boldsymbol{y}$ includes $\mathrm{HCHO}$ in the $\mathrm{HCN}$ scenario.

Figure 4 plots columns of the Jacobian, and it shows that ozone is more sensitive to changes in emissions during the afternoon and that $\mathrm{CO}$ and $\mathrm{NO}_{2}$ respond to changes in emissions during the rush hour periods.

The key assumption in using the Jacobian is that changes in the emissions can be described (see Rodgers (2000)) approximately by

$\mathbf{F}(\boldsymbol{x})-\mathbf{F}(\boldsymbol{x}+\delta \boldsymbol{x}) \approx \mathbf{K} \delta \boldsymbol{x}$.

This assumption has been validated using finite differencing (results not shown) to compare to solutions derived from the right side of Eq. (17).

\subsubsection{Emission error characterisation}

We calculate various statistics to determine the emission estimation performance. First, we determine the a posteriori emission parameter error covariance, which is defined (see Rodgers (2000)) by

$E\left[\widetilde{\boldsymbol{x}} \widetilde{\boldsymbol{x}}^{\mathrm{T}}\right]=\left(\mathbf{S}_{\mathrm{a}}^{-1}+\mathbf{K}^{\mathrm{T}} \mathbf{S}_{\mathrm{n}}^{-1} \mathbf{K}\right)^{-1}$.

Next, we calculate the emission averaging kernel defined by

$\mathbf{A}=\left(\mathbf{S}_{\mathrm{a}}^{-1}+\mathbf{K}^{\mathrm{T}} \mathbf{S}_{\mathrm{n}}^{-1} \mathbf{K}\right)^{-1} \mathbf{K}^{\mathrm{T}} \mathbf{S}_{\mathrm{n}}^{-1} \mathbf{K}$

and the degrees of freedom of signal that is calculated via

d.o.f. $=\operatorname{Tr}(\mathbf{A})$, 

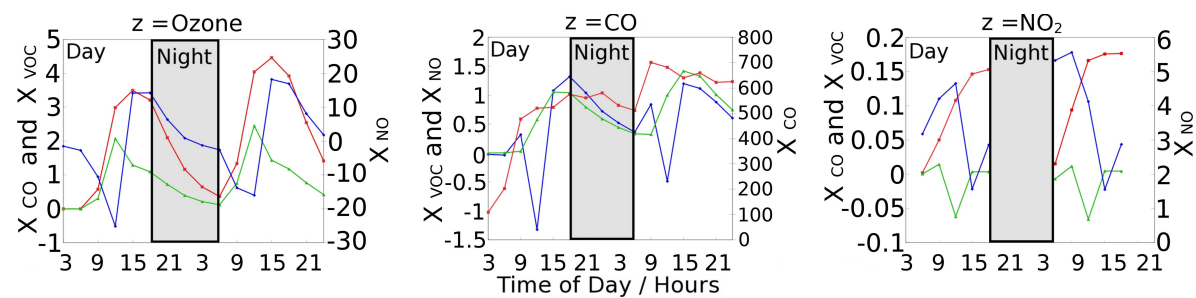

Figure 4. These plots show the columns of the Jacobian matrix, $\mathbf{K}$, that correspond to the perturbations of the three observed species in scenario OCN. Ozone is shown on the left, $\mathrm{CO}$ in the middle, and $\mathrm{NO}_{2}$ on the right. This Jacobian is for the $x_{\mathrm{NO}}=1.25$ emission scenario. The shaded area represents observations made during the night. $\mathrm{NO}_{2}$ observations made using visible remote-sensing instruments can only function during the daytime, so there is no need to include a row in the Jacobian corresponding to night-time $\mathrm{NO}_{2}$ observations. The blue, red, and green solid lines represent $q_{Z}(\boldsymbol{x}, t) / \partial x_{\mathrm{NO}}, q_{Z}(\boldsymbol{x}, t) / \partial x_{\mathrm{CO}}$, and $q_{Z}(\boldsymbol{x}, t) / \partial x_{\mathrm{VOC}}$, respectively. The $y$ axes on the left and right represent the different perturbations to $x$.

where both of these diagnostics provide information on the resolution of the emission retrieval, i.e. the ability of the estimate to uniquely distinguish between the emissions of individual species. The notation $\operatorname{Tr}(\mathbf{A})$ indicates the trace of a matrix. While the diagonals of $\mathbf{A}$ represent the sensitivity of $\hat{x}_{i}$ to $x_{i}$, the d.o.f. represents the number of separate emission parameters that can be uniquely retrieved.

\subsubsection{Ozone prediction error characterisation}

Using the a posteriori emission error, we can determine the a posteriori ozone prediction error during the prediction period. In order to do this we need to define a new Jacobian matrix, $\mathbf{K}^{\prime}$, that defines the forward photochemical response during the prediction and monitoring period (day 3 ) to perturbations in the emissions. Thus, $\mathbf{K}$ and $\mathbf{K}^{\prime}$ simply differ because $\mathbf{K}$ describes the model response during the observation period as opposed to the prediction and monitoring period. Each element of $\mathbf{K}^{\prime}$ is $\partial q_{z}\left(\boldsymbol{x}, t_{j}\right) / \partial \boldsymbol{x}_{i}$, where $j$ is the index of time denoting when the model is sampled on the third day. The a posteriori ozone prediction error covariance for the third day can be determined by

$\mathbf{E}\left[\widetilde{\boldsymbol{q}} \widetilde{\boldsymbol{q}}^{\mathrm{T}}\right]=\mathbf{K}^{\prime} \mathbf{E}\left[\widetilde{\boldsymbol{x}} \widetilde{\boldsymbol{x}}^{\mathrm{T}}\right] \mathbf{K}^{\prime \mathrm{T}}$.

\subsection{Summary of experiments}

We describe all of the experiments that we perform for the uncertainty analysis (Sect. 3.1) in Table 6. In each experiment we test a range of different observation characteristics using different parameters. To give an example, for the $\mathrm{CN}$ observing scenario we test the model forecast uncertainties across the nine values of $x_{\mathrm{NO}}$ (i.e. 0.5-2.5 with increments of 0.25 ) and for eight different levels of observing error $(\beta=0.01-5$; equivalent to $1,5,10,25,50,100,250$, and $500 \%$ relative error). Thus, we perform 72 separate tests for this experiment and for the OCN and $\mathrm{HCN}$ scenarios as well. However, for the experiment comparing $\mathrm{HCN}$ and $\mathrm{OCN}$ we carry out three separate tests where we scale $\mathrm{HCHO}$ observa- tion noise relative to the other species. We test three different scalings: $50 \%$ lower, the same, and $50 \%$ higher noise.

Section 3.2 is dedicated to sensitivity studies using the full 4D-var data assimilation forecast system. In Sect. 3.2.1 we demonstrate the ability of the 4D-var data assimilation forecast system to forecast ozone when using the three observation scenarios $\mathrm{CN}, \mathrm{OCN}$, and $\mathrm{HCN}$. For these experiments we use observations made at $3 \mathrm{~h}$ intervals and using $\beta=0.1$.

Next, in Sect. 3.2.2, we define a range of different $k(t)$ scenarios in order to probe the emission solution and ozone forecast sensitivity to the assumed diurnal emission variability. These alternative $k(t)$ scenarios and the standard emission variability are shown in Fig. 1. In each test we perform the $4 \mathrm{D}$-var data assimilation forecast using the alternative $k(t)$ scenario while still assuming that the standard emission variability is representative of the true state. We perform this test using the OCN scenario, observing at $3 \mathrm{~h}$ intervals and with $\beta=0.1$.

When conducting the VOC emission inversion, we represent VOC emission uncertainties as ethene emission uncertainties (rather than a more diverse range of VOCs). In Sect. 3.2.3 we test that assumption using a sensitivity analysis by assuming VOC emission errors for ethane instead of ethene. Again, we perform this test for the OCN scenario, observing at a $3 \mathrm{~h}$ frequency and with $\beta=0.1$.

\section{Results}

\subsection{Uncertainty analyses}

\subsubsection{Assessing observations of $\mathrm{CO}, \mathrm{NO}_{2}$, ozone, and $\mathrm{HCHO}$ and the influence of observation error}

\section{Emission error characterisation and ozone prediction error}

In this section we examine the choice of which species to observe in order to best constrain the emissions and improve the ozone prediction, and we look at the three scenarios $\mathrm{CN}$, 


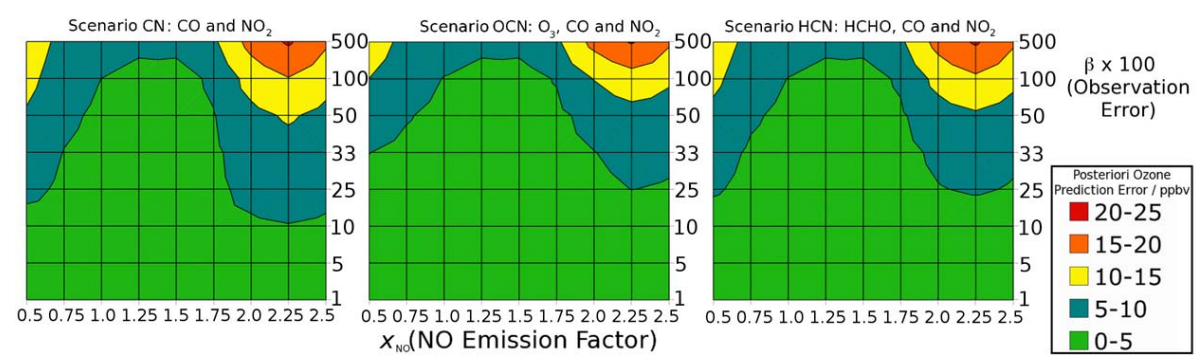

Figure 5. Ozone a posteriori prediction errors across the complete range of parameter space for $x_{\mathrm{NO}}(0.5-2.5)$ on the $x$ axis and $\beta(0.1-$ 5) along the $y$ axis with each panel presenting the results from the three observing scenarios $\mathrm{CN}$, OCN and HCN. The coloured contours represent the a posteriori prediction error in units of ppbv. The green and red colours indicate low and high levels of a posteriori ozone prediction error, respectively.

Table 6. List and details of all of the experiments carried out as part of the uncertainty analysis. The experiment details include the observed species, $x_{\mathrm{NO}}$ emission factors (see Table 2 for the full list), the observation noise, $\beta$, and the observing frequency. The eight different values of $\beta$ are $0.01,0.05,0.1,0.25,0.5,1.0,2.5$, and 5.0. These fractional errors are relative to the average species mixing ratios over all of the photochemical scenarios (see Table 4). The observing noises are identical for each compound within a particular scenario unless otherwise stated. All of the results from these experiments are described in Sect. 3.1. We also include short notes describing other aspects of the experiments. The table includes a list of the precise sections where the different experiments are discussed.

\begin{tabular}{|c|c|c|c|c|c|c|}
\hline Experiment & Section & $\begin{array}{l}\text { Observed } \\
\text { species }\end{array}$ & $\begin{array}{l}x_{\mathrm{NO}} \\
\text { scenarios }\end{array}$ & $\begin{array}{l}\text { Observation } \\
\text { noise }(\beta)\end{array}$ & $\begin{array}{l}\text { Observing } \\
\text { frequency }\end{array}$ & Notes \\
\hline $\mathrm{CN}$ & $\begin{array}{l}\text { First and third subsec- } \\
\text { tion of Sect. } 3.1 .1\end{array}$ & $\mathrm{CO}$ and $\mathrm{NO}_{2}$ & $\begin{array}{l}\text { Nine } x_{\mathrm{NO}} \\
\text { scenarios } \\
(0.5-2.5)\end{array}$ & $\begin{array}{l}\text { Eight } \beta \text { values } \\
(0.01-5.0)\end{array}$ & $3 \mathrm{~h}$ & \\
\hline $\mathrm{OCN}$ & $\begin{array}{l}\text { First and third subsec- } \\
\text { tion of Sect. } 3.1 .1\end{array}$ & $\begin{array}{l}\text { Ozone, } \mathrm{CO} \text { and } \\
\mathrm{NO}_{2}\end{array}$ & $\begin{array}{l}\text { Nine } x_{\mathrm{NO}} \\
\text { scenarios } \\
(0.5-2.5)\end{array}$ & $\begin{array}{l}\text { Eight } \beta \text { values } \\
(0.01-5.0)\end{array}$ & $3 \mathrm{~h}$ & \\
\hline $\mathrm{HCN}$ & $\begin{array}{l}\text { First and third subsec- } \\
\text { tion of Sect. } 3.1 .1\end{array}$ & $\begin{array}{l}\mathrm{HCHO}, \mathrm{CO} \text { and } \\
\mathrm{NO}_{2}\end{array}$ & $\begin{array}{l}\text { Nine } x_{\mathrm{NO}} \\
\text { scenarios } \\
(0.5-2.5)\end{array}$ & $\begin{array}{l}\text { Eight } \beta \text { values } \\
(0.01-5.0)\end{array}$ & $3 \mathrm{~h}$ & \\
\hline $\mathrm{HOCN}$ & $\begin{array}{l}\text { First subsection of } \\
\text { Sect. 3.1.1 }\end{array}$ & $\begin{array}{l}\mathrm{HCHO}, \text { ozone, } \\
\mathrm{CO} \text { and } \mathrm{NO}_{2}\end{array}$ & $\begin{array}{l}\text { Nine } x_{\mathrm{NO}} \\
\text { scenarios } \\
(0.5-2.5)\end{array}$ & $\begin{array}{l}\text { Eight } \beta \text { values } \\
(0.01-5.0)\end{array}$ & $3 \mathrm{~h}$ & Results not shown in any figure \\
\hline $\begin{array}{l}\text { Comparison between } \\
\mathrm{HCN} \text { and } \mathrm{OCN} \\
\left(E_{\mathrm{HCN}}-E_{\mathrm{OCN}}\right)\end{array}$ & $\begin{array}{l}\text { Second subsection of } \\
\text { Sect. } 3.1 .1\end{array}$ & $\begin{array}{l}\mathrm{HCHO} \text {, ozone, } \\
\mathrm{CO} \text { and } \mathrm{NO}_{2}\end{array}$ & $\begin{array}{l}\text { Nine } x_{\mathrm{NO}} \\
\text { scenarios } \\
(0.5-2.5)\end{array}$ & $\begin{array}{l}\text { Eight } \beta \text { values } \\
(0.01-5.0)\end{array}$ & $3 \mathrm{~h}$ & $\begin{array}{l}\text { Three different scenarios tested } \\
\text { each using different } \mathrm{HCHO} \text { ob- } \\
\text { servation noise }\end{array}$ \\
\hline $\begin{array}{l}\text { Observing frequency } \\
\text { experiment }\end{array}$ & Sect. 3.1 .2 & $\begin{array}{l}\text { Ozone, } \mathrm{CO} \text { and } \\
\mathrm{NO}_{2}\end{array}$ & $\begin{array}{l}\text { Nine } x_{\mathrm{NO}} \\
\text { scenarios } \\
(0.5-2.5)\end{array}$ & $\beta=0.25$ & $\begin{array}{l}\text { Six frequencies tested: } 1,3 \text {, } \\
6,12,18 \text {, and } 24 \mathrm{~h}\end{array}$ & \\
\hline $\begin{array}{l}\text { Observing time } \\
\text { experiment }\end{array}$ & Sect. 3.1 .2 & $\begin{array}{l}\text { Ozone, } \mathrm{CO} \text { and } \\
\mathrm{NO}_{2}\end{array}$ & $\begin{array}{l}\text { Nine } x_{\mathrm{NO}} \\
\text { scenarios } \\
(0.5-2.5)\end{array}$ & $\beta=0.25$ & $3 \mathrm{~h}$ & $\begin{array}{l}16 \text { different scenarios tested; } \\
\text { observations are removed at } \\
\text { different times in each case }\end{array}$ \\
\hline
\end{tabular}

OCN, and HCN in order to do this. Table 6 describes the parameter space we sample in each of these scenarios and it describes other important aspects of the forecast system setup, i.e. the values of $x_{\mathrm{NO}}$ and $\beta$ and the pseudo-observation observing frequency.

These results include the a posteriori ozone prediction error (calculated by Eq. 21) and the a posteriori emission parameter error (calculated by Eq. 18). We limit our analysis of the observed species to ozone, $\mathrm{CO}, \mathrm{NO}_{2}$, and $\mathrm{HCHO}$ because these gases are monitored by both ground stations and satellites.

Figure 5 presents the a posteriori ozone prediction errors across the complete range of parameter space and, in each panel, the results from the three observing scenarios. All of the scenarios exhibit similar general behaviour in the derived a posteriori ozone prediction errors: a first maximum in ozone prediction uncertainty in the $\mathrm{NO}_{x}$-limited scenarios $\left(x_{\mathrm{NO}}=0.5-0.75\right)$, with a consistent minimum in ozone prediction error in the transition region that is both $\mathrm{NO}_{x}$ and VOC limited $\left(x_{\mathrm{NO}}=1.0-1.75\right)$ and a second larger maximum in ozone prediction uncertainty in the VOC-limited regime $\left(x_{\mathrm{NO}}=2-2.5\right.$ ). Scenario $\mathrm{CN}$ (observing only $\mathrm{CO}$ and $\mathrm{NO}_{2}$ ) yields the highest a posteriori ozone prediction uncertainties of the three scenarios across the range of NO emission scenarios. The inclusion of ozone and HCHO observations in the $\mathrm{OCN}$ and $\mathrm{HCN}$ scenarios, respectively, reduces the a posteriori ozone prediction uncertainties compared to those from the $\mathrm{CN}$ scenario. Scenarios $\mathrm{OCN}$ and $\mathrm{HCN}$ both 


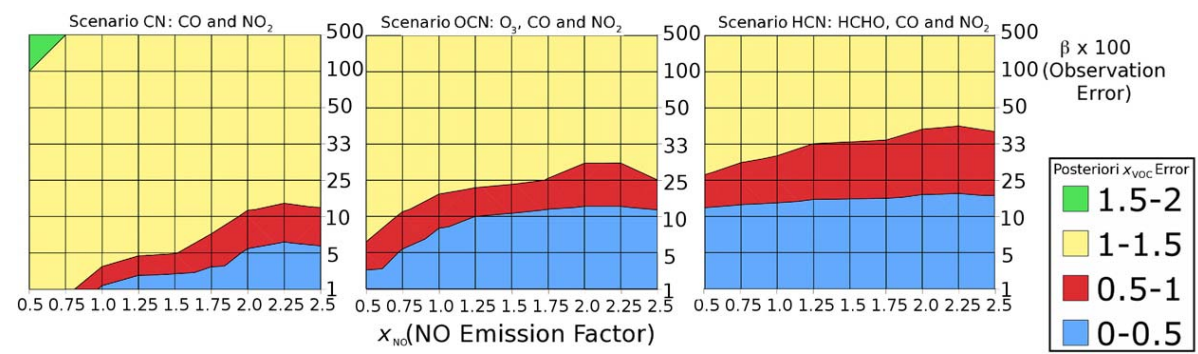

Figure 6. $x_{\mathrm{VOC}}$ a posteriori errors across the complete range of parameter space for $x_{\mathrm{NO}}(0.5-2.5)$ on the $x$ axis and $\beta$ (0.1-5) along the $y$ axis with each panel presenting the results from the three observing scenarios A-C. The coloured contours represent the a posteriori error. To allow comparison of the error in $x_{\mathrm{VOC}}$ to the true state, we note that the true state is defined as $x_{\mathrm{VOC}}=6.5$. The light blue and green colours indicate low and high a posteriori error on $x_{\mathrm{VOC}}$, respectively.

show significant improvement in the VOC-limited emission scenarios $\left(x_{\mathrm{NO}}=2.0-2.5\right)$, with each outperforming the $\mathrm{CN}$ scenario by up to $2.4 \mathrm{ppbv}$. Scenarios $\mathrm{OCN}$ and $\mathrm{HCN}$ diverge from one another when $x_{\mathrm{NO}}=2.0$, which represents the lowest $x_{\mathrm{NO}}$ factor that is still VOC limited. In this case, scenario OCN outperforms scenario $\mathrm{HCN}$ by up to $1.4 \mathrm{ppbv}$. Under $\mathrm{NO}_{x}$-limited conditions $\left(x_{\mathrm{NO}}=0.5-1.0\right)$, the $\mathrm{OCN}$ scenario a posteriori ozone prediction errors show a strong improvement relative to the $\mathrm{CN}$ scenario $(2.6 \mathrm{ppbv})$ and a slightly more modest improvement relative to the HCN scenario (1.9 ppbv).

We will now focus on explaining these differences in the a posteriori ozone prediction error highlighted above. To gain further insight into this behaviour, Figs. 6 and 7 show the a posteriori error for $x_{\mathrm{NO}}$ and $x_{\mathrm{VOC}}$. Note that the a posteriori error for $x_{\mathrm{CO}}$ (not shown) is invariant with respect to the photochemical regime and is therefore unable to explain any of the observed variability in ozone prediction error over varying $x_{\mathrm{NO}}$

Figure 6 shows that scenario $\mathrm{HCN}$ is able to reduce $x_{\mathrm{VOC}}$ a posteriori errors over the largest range of $\mathrm{NO}$ emission scenarios, followed by scenario OCN and scenario $\mathrm{CN}$. This reduction in VOC emission uncertainty in scenario $\mathrm{HCN}$ explains why this scenario shows reduced a posteriori ozone prediction error (by up to $2.4 \mathrm{ppbv}$ ) compared to the $\mathrm{CN}$ scenario under VOC-limited conditions. Despite HCHO observations overall providing a better constraint on VOC emission uncertainties under all conditions, this improved constraint only leads to lower a posteriori ozone prediction error compared to the OCN scenario in the transition region regimes $\left(x_{\mathrm{NO}}=1.0-1.75\right)$ (see Fig. 8, central plot) and under the most VOC-limited conditions $\left(x_{\mathrm{NO}}>2.0\right)$. The exception to this behaviour occurs at $x_{\mathrm{NO}}=2.0$; despite the $\mathrm{HCN}$ scenario showing lower $x_{\mathrm{VOC}}$ a posteriori errors compared to the OCN scenario, the HCN scenario shows higher a posteriori ozone prediction error. This occurs because the a posteriori ozone prediction error is also sensitive to the a posteriori NO emission uncertainties under VOC-limited conditions, and ozone is better than $\mathrm{HCHO}$ at constraining the $\mathrm{NO}$ emission uncertainties.
Figure 7 illustrates that the OCN scenario exhibits the smallest a posteriori $\mathrm{NO}$ emission parameter errors compared to any of the other observing scenarios. This is particularly pronounced under $\mathrm{VOC}$-limited and $\mathrm{NO}_{x}$-limited conditions. Therefore, ozone is better able to constrain NO emission uncertainties as compared with $\mathrm{HCHO}$ under all photochemical conditions, which is because ozone is always more sensitive to changes in $\mathrm{NO}$ emissions than $\mathrm{HCHO}$. Note, in the case of VOC-limited conditions, ozone is anticorrelated with $\mathrm{NO}$ emissions. As a direct result of this, the OCN scenario ozone a posteriori prediction errors are 2.5 and $1.9 \mathrm{ppbv}$ lower than the $\mathrm{CN}$ and $\mathrm{HCN}$ scenarios, respectively, while under $\mathrm{NO}_{x}$ limited conditions. Under VOC-limited conditions, the OCN scenario shows a posteriori ozone prediction errors that are $2.4 \mathrm{ppbv}$ lower than for the $\mathrm{CN}$ scenario. The improved estimation of the $\mathrm{NO}$ emissions in the OCN scenario compared to the $\mathrm{HCN}$ scenario only leads to reduced a posteriori ozone prediction errors (by $1.4 \mathrm{ppbv}$ ) for the $x_{\mathrm{NO}}=2.0$ emission case (see Fig. 8). This one exception is because VOC emission errors dominate the ozone prediction uncertainty for the other VOC-limited cases.

We now briefly explore the benefits of combining all four of the observed species $\left(\mathrm{CO}, \mathrm{NO}_{2}\right.$, ozone, and $\left.\mathrm{HCHO}\right)$ to make the HOCN scenario. This scenario can improve ozone prediction errors by up to 2.9 and $3.1 \mathrm{ppbv}$ under $\mathrm{NO}_{x}$ and VOC-limited conditions, respectively, compared to the $\mathrm{CN}$ scenario. Combining ozone and $\mathrm{HCHO}$ observations slightly improves ozone prediction errors by up to 0.3 and $0.8 \mathrm{ppbv}$ under $\mathrm{NO}_{x}$ and VOC-limited conditions, respectively, compared to the OCN scenario. The differences between the ozone and $\mathrm{HCHO}$ combined scenario and the OCN scenario under VOC-limited conditions further highlight the potential for $\mathrm{HCHO}$ observations to improve ozone prediction errors under the most VOC-limited conditions.

Until now, we have not directly discussed the impact of $\mathrm{CO}$ observations or of the resolution of $\mathrm{CO}$ emission uncertainties within the assimilation framework. We do not show a figure here, but a posteriori $\mathrm{CO}$ emission uncertainties are almost invariant with respect to photochemical regime and to the observing scenario $(\mathrm{CN}, \mathrm{OCN}$, or $\mathrm{HCN})$. However, the a 


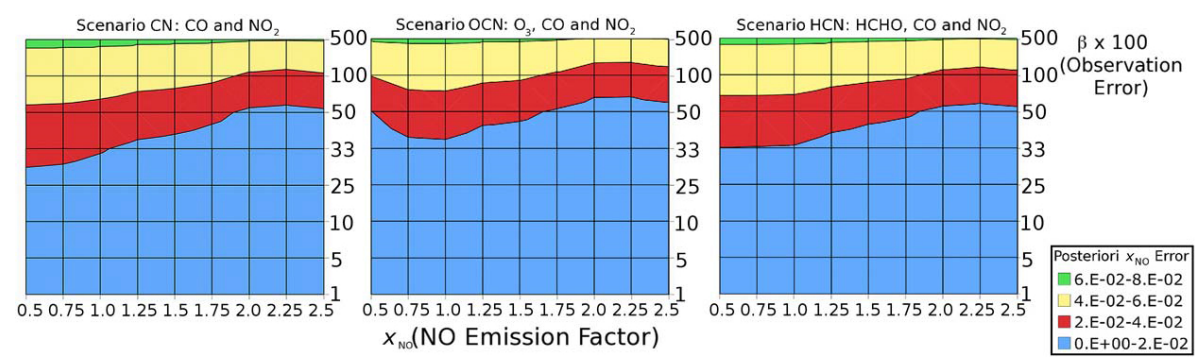

Figure 7. $x_{\mathrm{NO}}$ a posteriori errors across the complete range of parameter space for $x_{\mathrm{NO}}(0.5-2.5)$ on the $x$ axis and $\beta$ (0.1-5) along the $y$ axis with each panel presenting the results from the three observing scenarios $\mathrm{CN}$, OCN and HCN. The coloured contours represent the a posteriori error. To allow comparison of the error in $x_{\mathrm{NO}}$ to the true state, we note that the true state is defined as the $x$ axis value. The light blue and green colours indicate low and high a posteriori error on $x_{\mathrm{NO}}$, respectively.

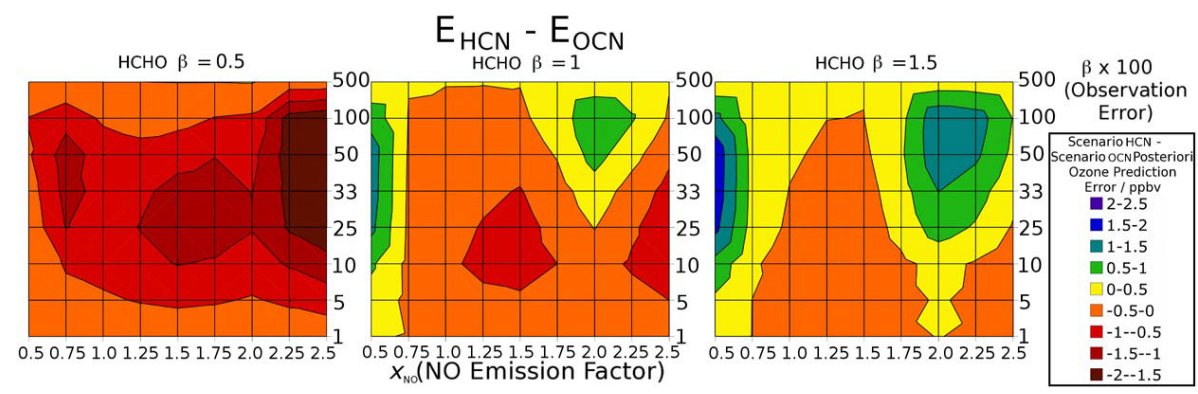

Figure 8. The difference between the scenario $\mathrm{HCN}$ and $\mathrm{OCN}$ a posteriori ozone prediction error for a range of assumed $\mathrm{HCHO}$ observing error scenarios. In all of the previous analyses and results, $\beta$ has been identical for all observed species, but in this sensitivity analysis we scale $\beta$ for HCHO independently from the other observed species. From left to right HCHO observing errors are assumed to be 50, 100, and $150 \%$ of the observing error for the other species. Thus, the right-hand panel indicates a scenario with HCHO observations of poorer quality compared to the other species and represents the difference in ozone prediction error between the right and middle panels of Fig. 5; the left panel indicates a rather optimistic case with assumed $\mathrm{HCHO}$ observation errors less than the other observed species errors. The dark red and dark blue contour colours indicate the negative and positive differences between the scenario HCN and OCN a posteriori ozone prediction error, respectively.

posteriori CO emission uncertainties increase from $1 \times 10^{-5}$ to 0.1 as the observing noise increases from $\beta=0.01$ to $\beta=1.0$, respectively. According to the sensitivity of ozone to $x_{\mathrm{CO}}$ in the Jacobian $\mathbf{K}^{\prime}$, these relatively low levels of $\mathrm{CO}$ emission uncertainty would only lead to perturbations in ozone of $0.5 \mathrm{ppbv}$ at most. For the case with the highest amount of noise, $\beta=5.0$, the a posteriori $\mathrm{CO}$ emission uncertainty reaches 1.1. Again, using $\mathbf{K}^{\prime}$, we can estimate that this larger level of $\mathrm{CO}$ emission uncertainty could lead to about a 5 ppbv perturbation in ozone. Therefore, only the $\beta=5.0$ noise scenario leads to large enough a posteriori $\mathrm{CO}$ emission uncertainties that can have a significant effect on a posteriori ozone prediction errors.

\section{Sensitivity test for degraded HCHO observations}

The standard HCN scenario described above assumes that the relative observing errors for $\mathrm{HCHO}$ are the same as for the other gases. However, within the context of satellite observations, the quality of $\mathrm{HCHO}$ observations are likely to be degraded relative to ozone, for instance. This is likely due to the relative magnitude of the absorption cross-sections and interferences from other absorbing gases. We therefore perform a sensitivity test whereby we apply an upward scaling factor to the $\beta$ of HCHO to increase it by $50 \%$ relative to the other observed gases in the standard HCN scenario (see the experiment "comparison between $\mathrm{HCN}$ and OCN" in Table 6 for further details). Figure 8 shows that scenario HCN only has lower a posteriori ozone prediction uncertainties over the full range of $\mathrm{NO}$ emission scenarios under the optimistic scenario of lower HCHO observation uncertainties ( $\beta$ of HCHO is set to be $50 \%$ lower than that of ozone) and that in the other scenarios, which we assume would be closer to reality, scenario $\mathrm{HCN}$ only outperforms scenario $\mathrm{OCN}$ in the transition region and for the most VOC-sensitive regimes. Under the assumptions of lower ozone observing uncertainty, OCN out performs scenario $\mathrm{HCN}$ in the $\mathrm{NO}_{x}$ - and VOC-limited regimes by up to $1.9 \mathrm{ppbv}$. 


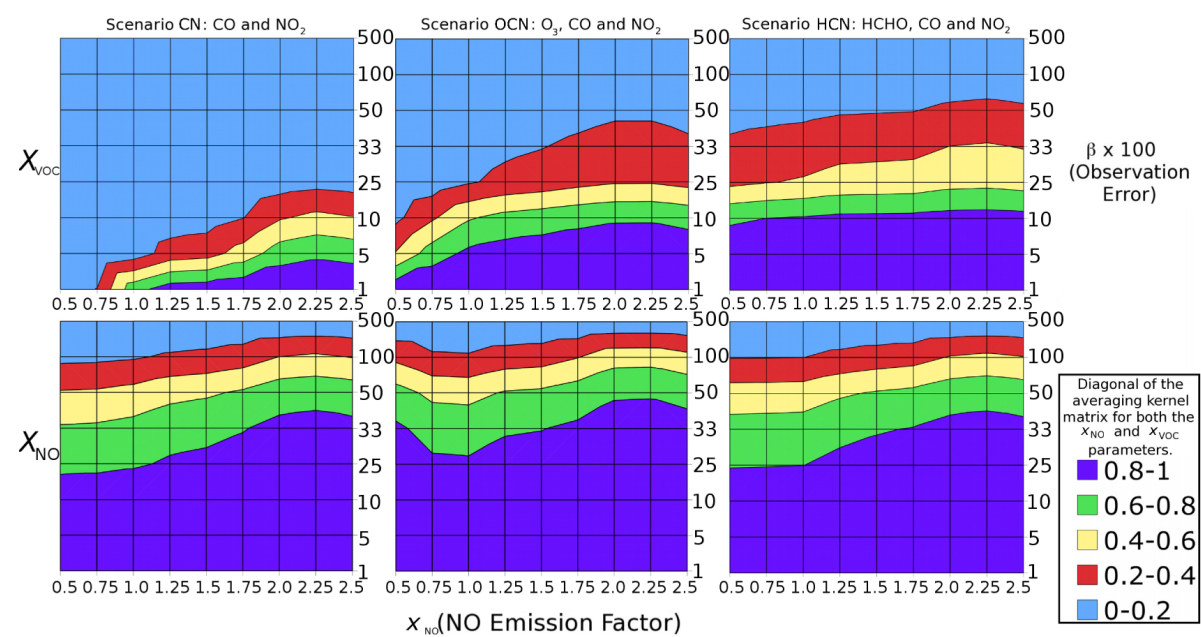

Figure 9. The diagonal of the emission averaging kernel for $x_{\mathrm{NO}}$ in the lower row and $x_{\mathrm{VOC}}$ in the upper row. Each column represents a different observing scenario $(\mathrm{CN}, \mathrm{OCN}$, and $\mathrm{HCN})$. The $x$ axis denotes the varying value of $x_{\mathrm{NO}}$ and the $y$ axis shows $\beta(0.1-5)$. The contours represent the varying magnitude of the diagonal of the averaging kernel matrix from 0 to 1 . The purple and light blue contour colours indicate high and low values of the diagonal of the averaging kernel matrix, respectively.

\section{Averaging kernel and degrees of freedom of signal}

Following from Sect. "Emission error characterisation and ozone prediction error", we now characterise the emission estimate using the emission averaging kernel and degrees of freedom of signal diagnostics. The emission averaging kernel (Eq. 19) represents the sensitivity of the retrieved emission parameters along the diagonal, i.e. for a particular species, $i$, to changes in the real emission parameter for species, $i$. This analysis is carried out for the $\mathrm{CN}, \mathrm{OCN}$, and $\mathrm{HCN}$ scenarios (refer to Table 6 for details). Figure 9 shows the respective diagonals of the emission averaging kernel (for $x_{\mathrm{VOC}}$ and $x_{\mathrm{NO}}$ ) varying in a manner consistent with the a posteriori parameter errors as shown in Figs. 6 and 7. A comparison of the lower panels indicates that the NO emission parameter estimate using the $\mathrm{OCN}$ observing scenario is more sensitive to the true state of the $\mathrm{NO}$ emission parameter under both $\mathrm{NO}_{x}$ limited and VOC-limited conditions than any of the other observing scenarios. The top panels show that the VOC parameter estimate shows the highest sensitivity to the true state of the VOC emission parameter using the $\mathrm{HCN}$ observing scenario.

Consistent with the averaging kernel, the emission inversion degrees of freedom of signal (see Eq. 20, results not shown) indicates that the HCN scenario is better able to retrieve and resolve the three separate emission parameters compared to the OCN scenario. This is because HCHO provides a better constraint on VOC emissions over a wider range of $x_{\mathrm{NO}}$ and $\beta$. However, ozone in general constrains ozone precursor emissions across a wider variety of emission parameters, specifically for $x_{\mathrm{NO}}$, which allows ozone observations to yield better a posteriori ozone prediction errors. The OCN scenario shows a decrease in the degrees of the freedom of signal under $\mathrm{NO}_{x}$-limited conditions due to the lack of sensitivity of the retrieval to the VOC emission parameter when using these observations.

\subsubsection{Observing time and observing frequency}

We now examine the sensitivity of the ozone prediction error to the removal of observations at different times during the day. (Refer to the observing time experiment in Table 6 for details.) Since the first observations are made at 00:00 LT, this means that, in practice, we run our tests by removing observations at 00:00, 03:00, 06:00 (all local time) and so on until each observation within the entire observing window (the first 2 days of simulation) has been tested.

Figure 10 shows that a posteriori ozone prediction errors are most sensitive to the removal of observations during the day particularly during the high-emission periods in the morning and afternoon rush hours and particularly so during the period of elevated ozone in the afternoon. The timing and magnitude of the sensitivity and its peak to observation removal varies according to the nine NO emission scenarios as well. In the more $\mathrm{NO}_{x}$-limited scenarios, $x_{\mathrm{NO}}=0.5-1.0$, the sensitivity to observation removal is distributed relatively evenly over the entire day. In the VOClimited regimes, $x_{\mathrm{NO}}=1.75-2.5$, the sensitivity to observation removal is more tightly distributed within the afternoon period and peaks between 15:00 and 18:00 LT even showing a broad maximum out to 20:00 LT under the most VOClimited conditions. The temporal variability in the maximum sensitivity to observation removal with changing photochemical regime is due to the timing of afternoon peak ozone concentrations. This is because across all of the photochemical regimes maxima in ozone sensitivity to perturbations in 


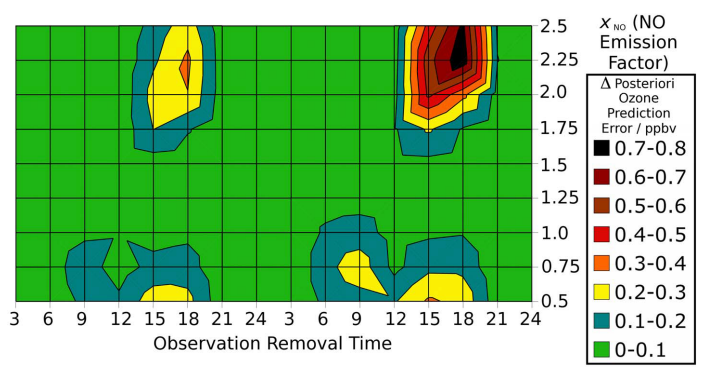

Figure 10. The absolute increase in a posteriori ozone prediction error between scenario $\mathrm{OCN}$ with $\beta=0.25$ and the same scenario with observations removed form specific times over the course of two days (perturbed case), e.g. 15:00 LT on the second day indicates that no observations were included in the analytical model calculation of a posteriori ozone prediction error for the perturbed case from 15:00 LT on the second day. The green and black colours indicate low and high values, respectively.

emissions coincide with the daytime peak ozone concentration (see Fig. 4). Observations made during these key periods are therefore better able to constrain the emissions uncertainties. Ozone concentrations peak later in the afternoon under more VOC-limited conditions compared to the $\mathrm{NO}_{x}$-limited conditions, thus explaining some of the variability in maximum sensitivity to observation removal with changing photochemical regimes.

Next, we address how observing frequency will affect the ozone prediction error. We run a series of sensitivity tests using a variety of observing frequencies ranging from once a day to once every hour. Table 6 provides a complete description of the observing frequency experiment. We carry out these tests across the full range of $\mathrm{NO}$ emission scenarios $\left(x_{\mathrm{NO}}=0.5-2.5\right.$ with increments of 0.25$)$ and with $\beta=0.25$. Figure 11 shows how a posteriori ozone prediction errors vary with changing observing frequency. Increasing observing frequency causes the largest decreases in a posteriori ozone prediction uncertainty in the VOC-limited regime and to a lesser extent in the $\mathrm{NO}_{x}$-limited regime due to the sensitivity of ozone prediction error to unresolved emission parameter errors in those regimes.

\subsection{Supporting sensitivity analyses}

\subsubsection{D-variational data assimilation}

We now demonstrate the performance of the 4D-variational data assimilation. Our 4D-var framework solves the nonlinear estimation problem in that it optimises the ozone precursor emissions and then estimates a posteriori ozone mixing ratios (the forecast). We run the system across the full range of photochemical conditions $\left(x_{\mathrm{NO}}=0.5-2.5\right)$ and for the $\mathrm{CN}, \mathrm{OCN}$ and $\mathrm{HCN}$ scenarios whilst assuming low levels of observational error $(\beta=0.1)$ represented in the observation error covariance matrix.
The results shown in Table 7 indicate that scenarios OCN and HCN yield acceptable prediction error under these idealised conditions $(\beta=0.1)$ within this prototype framework for all photochemical conditions. The more limited success of scenario $\mathrm{CN}$ (observations of $\mathrm{CO}$ and $\mathrm{NO}_{2}$ ) is due to the lower sensitivity of $\mathrm{CO}$ and $\mathrm{NO}_{2}$ observations to the emissions of VOCs across all $\mathrm{NO}_{x}$ emission scenarios and due to the low sensitivity of $\mathrm{CO}$ observations to the emissions of NO. The magnitude of the adjoint sensitivities guides the L-BFGS algorithm (Zhu et al., 1997) to the global minimum. In cases where the adjoint sensitivities are low, e.g. in VOC-limited conditions using the $\mathrm{CN}$ scenario, the optimisation routine may only be able to find a non-global minimum, which leads to larger a posteriori emission factor errors, $\hat{\boldsymbol{x}}-\boldsymbol{x t}$.

Table 7 indicates that there is variability in a posteriori peak ozone prediction error over changing photochemical regime and $x_{\mathrm{NO}}$ for each observing scenario $\mathrm{CN}, \mathrm{OCN}$, and $\mathrm{HCN}$. This variability with $x_{\mathrm{NO}}$ is due in part to the variations in modelled ozone sensitivity to the different ozone precursor emission parameters, $\partial q_{\mathrm{O}_{3}}(\boldsymbol{x}, t) / \partial x_{i}$, and the a posteriori emission parameter errors (i.e. $\hat{x}-x t$ ). Generally, the large sensitivity of predicted ozone to the emissions of ozone precursors, $\partial q_{\mathrm{O}_{3}}(\boldsymbol{x}, t) / \partial x_{i}$, combined with unresolved ozone precursor emission parameter errors can lead to larger a posteriori peak ozone prediction errors. For instance, in the $\mathrm{NO}_{x}$-limited regimes $\left(x_{\mathrm{NO}}=0.5-1.0\right)$ large residual error in the element of $\hat{\boldsymbol{x}}$ corresponding to NO emissions would lead to large a posteriori ozone errors.

One example of this phenomenon occurs in the case of photochemically VOC-limited scenarios (i.e. $x_{\mathrm{NO}}=1.75-$ 2.5). Table 8 shows the variability in a posteriori VOC emission errors with $x_{\mathrm{NO}}$ and observing scenario. For observing scenario $\mathrm{CN}$ there is a large unresolved error in $x_{\text {VOC }}$ (Table 8) as in this case the size of the adjoint sensitivities is insufficient to guide the L-BFGS algorithm to the global minimum, and the solutions represent local minima. This leads to a larger a posteriori ozone prediction error as compared to scenarios OCN and HCN (see Table 7), which are better able to resolve errors in VOC emissions.

There are also examples where ozone precursor emissions are poorly resolved, but this has only minimal impact on the ozone prediction error, $D$. This occurs for the OCN scenario when $x_{\mathrm{NO}}$ ranges from 1.25 to 1.5 . For these cases the unresolved error in $x_{\mathrm{VOC}}$ is larger than for many other situations. Again, this occurs because the L-BFGS algorithm is only able to find a local minimum. However, in these instances, the relatively low sensitivity of ozone to $x_{\mathrm{VOC}}$ means that the resulting ozone prediction errors are relatively low as well.

Thus, there is a rather complex set of factors interacting to cause these resulting a posteriori prediction errors, and the analysis of the results is limited to identifying relationships between the observing scenario, the photochemical regime, the adjoint sensitivities and the resulting ozone a posteriori prediction error. This demonstrates the utility of the analyti- 
Table 7. Initial peak ozone predictions, true-state peak ozone, initial guess ozone prediction error, and prediction error across the full range of $x_{\mathrm{NO}}\left(x_{\mathrm{NO}}\right.$ is in terms of unitless emission scaling factor) and the three observing scenarios CN, OCN and HCN. The ozone values and absolute differences in ozone mixing ratio are listed for 15:00 LT during the final day of the prediction model. $D$ represents the a posteriori prediction model error and $G$ represents the a priori and initial guess prediction error (see Fig. 3 for more details).

\begin{tabular}{|c|c|c|c|c|c|c|}
\hline$x_{\mathrm{NO}}$ Scenario & $q_{\mathrm{O}_{3}}\left(\boldsymbol{x}_{\mathrm{a}}, t^{\mu}\right)(\mathrm{ppbv})$ & $q_{\mathrm{O}_{3}}\left(\boldsymbol{x} \boldsymbol{t}, t^{\mu}\right)(\mathrm{ppbv})$ & $\begin{array}{r}G \\
\text { (ppbv) }\end{array}$ & $\begin{array}{r}D(\mathrm{ppbv}) \\
\text { scenario CN }\end{array}$ & $\begin{array}{r}D(\mathrm{ppbv}) \\
\text { scenario OCN }\end{array}$ & $\begin{array}{r}D(\mathrm{ppbv}) \\
\text { scenario } \mathrm{HCN}\end{array}$ \\
\hline 0.5 & 72.7 & 79.3 & -6.6 & -6.3 & -0.4 & -1.0 \\
\hline 0.75 & 81.3 & 89.7 & -8.4 & -8.3 & -0.5 & -0.7 \\
\hline 1.0 & 85.2 & 96.3 & -11.1 & -4.5 & -0.6 & -0.5 \\
\hline 1.25 & 85.5 & 100.3 & -15.1 & -3.3 & -0.6 & -0.3 \\
\hline 1.5 & 79.7 & 101.5 & -21.8 & -4.2 & -0.5 & -0.1 \\
\hline 1.75 & 66.1 & 98.7 & -32.6 & 2.2 & 0.3 & 0.2 \\
\hline 2.0 & 52.8 & 89.0 & -36.2 & 1.9 & 0.3 & 0.2 \\
\hline 2.25 & 43.6 & 73.0 & -29.4 & 1.4 & 0.3 & 0.2 \\
\hline 2.5 & 37.1 & 58.8 & -21.7 & 1.0 & 0.3 & 0.2 \\
\hline
\end{tabular}

Table 8. The a posteriori $x_{\mathrm{VOC}}$ error resulting from the $4 \mathrm{D}$ variational data assimilation. The table shows the variability in the a posteriori VOC emission error (in terms of unitless emission scaling factor) both with observing scenario and $\mathrm{NO}$ emission factor. Errors are represented as absolute errors of $x_{\mathrm{VOC}}$.

\begin{tabular}{rrrr}
\hline & \multicolumn{3}{c}{$\hat{x}_{\mathrm{VOC}^{-}} x_{\mathrm{VOC}}$} \\
\cline { 2 - 4 }$x_{\mathrm{NO}}$ & Scenario CN & Scenario OCN & Scenario HCN \\
\hline 0.5 & -6.4 & 0.40 & $8.5 \times 10^{-2}$ \\
0.75 & 9.1 & 0.33 & $5.0 \times 10^{-2}$ \\
1.0 & -2.7 & -0.01 & $3.3 \times 10^{-2}$ \\
1.25 & -1.6 & 9.87 & $-2.6 \times 10^{-2}$ \\
1.5 & -1.7 & 2.71 & $-3.6 \times 10^{-2}$ \\
1.75 & 0.77 & 0.21 & $2.4 \times 10^{-2}$ \\
2.0 & 0.54 & 0.20 & $3.3 \times 10^{-2}$ \\
2.25 & 0.40 & 0.18 & $4.5 \times 10^{-2}$ \\
2.5 & 0.35 & 0.18 & $4.8 \times 10^{-2}$ \\
\hline
\end{tabular}

cal model in allowing a far more in-depth analysis. Overall, the 4D-variational data assimilation framework seems capable of resolving emission uncertainties and in turn reducing ozone prediction error. This successful demonstration of the framework is a necessary but not sufficient condition for systems based upon more complex photochemical models to have ozone predictive skill.

\subsubsection{Examining day-to-day variability and probing emission solution sensitivity to diurnal emission variability}

We investigate the sensitivity of the forward photochemical model ozone mixing ratios, obtained via the $4 \mathrm{D}$-var ozone prediction and the $4 \mathrm{D}$-var emissions estimate, to a range of assumed emission diurnal profiles. We use the following profiles selected arbitrarily to test the model sensitivity: constant, sine wave, square wave, and offsets of the exist-

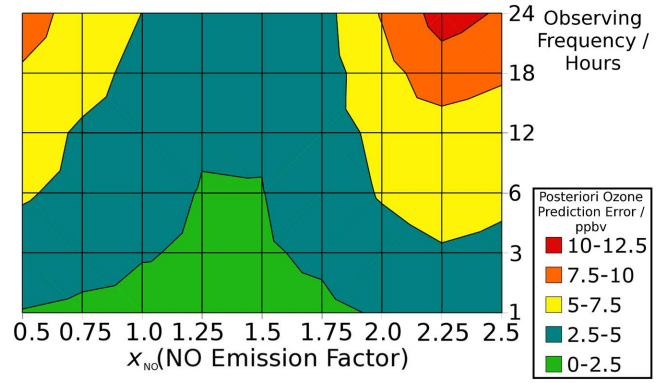

Figure 11. The a posteriori ozone prediction error for a variety of observation frequency scenarios ranging from an observing frequency of $1 \mathrm{~h}$ to once per day. These were calculated for scenario OCN with $\beta=0.25$. The green and red colours indicate low and high levels of a posteriori ozone prediction error, respectively.

ing profile by 1 and $2 \mathrm{~h}$ shifts both forward and backward in time (see Fig. 1). These alternative emission profiles are taken to represent the new true state, $\boldsymbol{x t}$, (using $x_{\mathrm{NO}}=0.75$ ) and are used to generate the pseudo-observations (using $\beta=0.1)$. We then attempt the assimilation using the pseudoobservations generated from the alternative emission scenarios whilst assuming that the emissions temporal variability is the standard variability. The alternate emission profiles test the robustness of the $4 \mathrm{D}$-variational data assimilation method to diurnal uncertainty in the emissions.

Table 9 indicates that the forward model shows peak ozone mixing ratios diverging from the base case run (standard assumed emission variability with $x_{\mathrm{NO}}=0.75$ ) by up to $10.6 \mathrm{ppbv}$ and that the forward-model ozone mixing ratios are sensitive to the assumption of the diurnal emission variability. In addition, Table 9 shows that the 4D-variational data assimilation is able to achieve a posteriori peak ozone prediction errors of up to $2.4 \mathrm{ppbv}$ relative to the true state, as defined by the perturbed scenario, despite using the unperturbed diurnal emission scenario as its emission variabil- 
Table 9. Results from a study exploring the sensitivity of the 4D-variational data assimilation forecast of peak ozone to varying assumptions regarding, $k(t)$, the diurnal variability in ozone precursor emissions. Note that in each scenario the cumulative daily emission burden remains constant for each scenario and thus each scenario has identical $\overline{E(t)}$. The overbar indicates that this represents the mean value. The table shows (in ppbv) the modelled ozone for each alternative $k(t)$ scenario, the differences in true-state peak ozone between these alternative $k(t)$ scenarios and the standard $k(t)$ scenario, and the absolute errors of the a posteriori ozone predictions of these alternative $k(t)$ scenarios relative to both the standard and alternative $k(t)$ scenario true states. All of the ozone mixing ratios are listed for 15:00 LT during the final day of the prediction and monitoring period.

\begin{tabular}{lrrrr}
\hline $\begin{array}{l}\text { Assumed } k(t) \\
\text { scenario }\end{array}$ & $\begin{array}{r}\text { Alternative } \\
\text { emission } \\
\text { scenario } \\
\text { (ppbv) }\end{array}$ & $\begin{array}{r}\text { Alternative emission } \\
\text { scenario true state } \\
\text { - standard emission } \\
\text { scenario true } \\
\text { state (ppbv) }\end{array}$ & $\begin{array}{r}\text { Alternative ozone } \\
\text { prediction } \\
\text { standard true } \\
\text { state (ppbv) }\end{array}$ & $\begin{array}{r}\text { Alternative } \\
\text { ozone prediction } \\
- \text { alternative } \\
\text { true state (ppbv) }\end{array}$ \\
\hline Constant & 92.5 & 2.8 & 4.0 & 0.7 \\
Sine wave & 97.6 & 7.9 & 8.8 & 0.5 \\
Saw-tooth & 100.3 & 10.6 & 9.7 & -1.4 \\
Offset -1 & 93.8 & 4.2 & 4.7 & 0.1 \\
Offset -2 & 98.9 & 9.0 & 9.2 & -0.2 \\
Offset +1 & 86.2 & -3.5 & -4.9 & -1.4 \\
Offset +2 & 83.5 & -6.2 & -8.6 & -2.4 \\
\hline
\end{tabular}

ity. Although we only show the differences in the maximum ozone mixing ratios, this behaviour is reproduced in the ozone mixing ratios at other times during the sunlit day. This further confirms our general findings from these tests. Despite the relative success of the a posteriori peak ozone prediction (only a maximum ozone prediction error of $2.4 \mathrm{ppbv}$ ) under these more challenging conditions, the assimilation performs poorly in terms of the a posteriori emission factor error. Errors range up to 0.46 (18-92\%), 0.17 (17\%), and $7.0(108 \%)$ for $x_{\mathrm{NO}}, x_{\mathrm{CO}}$, and $x_{\mathrm{VOC}}$ (relative to true scaling factors of $0.5-5.0,1.0$, and 6.5 , respectively), and thus emission inversion success is strongly affected by errors in the assumed diurnal variability in ozone precursor emissions. In summary, we demonstrate forward-model ozone sensitivity to perturbations in the diurnal variability in ozone precursor emissions, relative insensitivity of the $4 \mathrm{D}$-variational data assimilation a posteriori prediction error to mismatches in the assumed versus observed diurnal variability in ozone precursor emissions, and sensitivity of the emissions inversion success to mismatches in the assumed versus true emissions variability.

\subsubsection{Emission inversion and ozone predictive skill sensitivity to VOC species selection}

We conducted a sensitivity test whereby we represent VOC emission uncertainties with uncertainties in the emission of ethane, which is a less reactive VOC compared to ethene. We found that the VOC emission inversion is severely degraded by building the Jacobian by perturbing $x_{\text {ethane }}$ as opposed to $x_{\text {ethene }}$ across the three scenarios. The a posteriori $x_{\mathrm{VOC}}$ parameter error relaxes to our chosen a priori of 1.5 to within one significant figure for most of the scenarios explored. However, this does not affect ozone prediction error since the degraded VOC emission uncertainty is mitigated by the lower reactivity of ethane compared to ethene. As a result, the sensitivity of ozone to that uncertainty is therefore lower.

\section{Discussion and conclusions}

We addressed a set of key questions to determine how characteristics of observations of ozone and its precursors affect one's ability to constrain ozone precursor emissions and consequently to predict ozone when using an idealised prognostic air quality model coupled to a data assimilation framework. These questions consisted of which species to observe, how well to observe them, how often to make observations, when to make them during the diurnal cycle, and how long to observe before making a prediction. Further to this, we were interested in how the answers to these questions changed according to varying photochemical regimes (from $\mathrm{NO}_{\mathrm{x}}-$ to VOC-limited conditions for ozone formation). These questions are relevant to determining, in a very coarse way, how the various observing platforms (e.g. LEO and GEO satellites) and ground monitoring networks are able to support air quality research and forecasting.

We used a framework consisting of a photochemical box model using idealised meteorology, its adjoint, and a 4Dvariational data assimilation system set-up to constrain ozone precursor emission uncertainties $\left(\mathrm{NO}_{x}, \mathrm{CO}\right.$, and VOCs). The photochemical box model used idealised meteorology that represented stagnant summer weather conditions. Using linear analysis to assess the framework's prediction uncertainties, we carried out a series of sensitivity analyses to test the performance of the forecasting framework under a range of different observing scenarios. This consisted of using vari- 
ous sets of pseudo-observations. We examined the effect of changing which four species were observed $\left(\mathrm{CO}, \mathrm{NO}_{2}\right.$ and $\mathrm{HCHO}, \mathrm{CO}$, and $\mathrm{NO}_{2}$ ), of varying the observation noise, of changing the observing frequency, and of changing the time during the day when observations are made.

We were able to demonstrate that the 4D-var framework was able to constrain ozone precursor emissions and consequently that it was able to reduce ozone prediction uncertainties and provide an adequate ozone forecast under the idealised conditions that we used. This therefore demonstrated our framework's relevance to future air quality forecasting systems that might utilise state of the art assimilation and observations made using either the ground station network or from orbiting satellites. Clearly, more difficulties and challenges remain before such a framework can be used in a realworld setting, such as how to incorporate averaging kernels of satellite retrievals into the assimilation system or accounting for representativity errors. Also, using the linear analysis to estimate the prediction uncertainties, we were able to derive a series of general conclusions that are discussed below.

\subsection{The effect of changing the observed species}

Our results show that the variability in ozone prediction error with both photochemical regime and observing species scenario $(\mathrm{CN}, \mathrm{OCN}$ and $\mathrm{HCN})$ is complex and no single observed species is ideal for all photochemical conditions.

Under $\mathrm{NO}_{x}$-limited conditions ozone prediction error is strongly controlled by the a posteriori NO emission errors, and therefore observations of $\mathrm{NO}_{2}$ and ozone would be highly advantageous. Ozone provides a particularly good constraint upon $\mathrm{NO}$ emissions under very $\mathrm{NO}_{x}$-limited and VOC-limited conditions. The value of $\mathrm{NO}_{2}$ observations in constraining $\mathrm{NO}$ emissions improves as the $\mathrm{NO}_{x}$ lifetime increases under the somewhat less $\mathrm{NO}_{x}$-limited conditions $\left(x_{\mathrm{NO}}=1.0-1.25\right)$. Much of the troposphere is in fact highly $\mathrm{NO}_{x}$-limited outside of the most polluted areas (Duncan et al., 2010).

Under VOC-limited conditions ozone prediction error is sensitive to both a posteriori $x_{\mathrm{NO}}$ (due to the anticorrelation of ozone to $\mathrm{NO}_{x}$ ) and $x_{\mathrm{VOC}}$ errors, and thus observations of ozone, $\mathrm{HCHO}$ and $\mathrm{NO}_{2}$ allow significant improvements in ozone prediction error. Assimilating ozone, therefore, allows constraints to be placed upon VOC and $\mathrm{NO}$ emission uncertainties. HCHO provides an excellent constraint upon reactive VOC emissions, which due to their reactivity are more relevant to air quality compared to less reactive VOCs. $\mathrm{NO}_{2}$ provides an excellent constraint upon $\mathrm{NO}$ emissions under VOC-limited conditions; more than under $\mathrm{NO}_{x}$-limited conditions due to the longer $\mathrm{NO}_{x}$ lifetime. Despite the fact that large geographical portions of the US are $\mathrm{NO}_{x}$-limited, a disproportionately large percentage of the population lives within or is exposed to ozone arising from VOC-limited conditions due to the significant extent of urbanisation within the US. Large urbanised areas of the south-west of the US that lack significant native vegetative biomass typically have a larger VOC-limited regime that extends over the urban as well as suburban areas. In contrast, US cities in the east are located in regions with often dense vegetative biomass, e.g. Atlanta, and thus the VOC-limited region is far more geographically limited to the urban centre itself. Therefore, improving ozone predictive skill within VOC-limited conditions will not yield forecasting improvements over a wide geographical area but will yield improvements within certain regions with large populations.

Our findings with respect to the utility of $\mathrm{NO}_{2}$ and $\mathrm{HCHO}$ observations for constraining $\mathrm{NO}_{x}$ and VOC emissions, respectively, and in turn for improving ozone estimation are broadly consistent with the findings of Zhang et al. (2008), who used satellite observations of $\mathrm{NO}_{2}$ and $\mathrm{HCHO}$ in conjunction with 4D-variational data assimilation to solve for $\mathrm{NO}_{2}$ and $\mathrm{HCHO}$ emissions and to improve the model's ozone estimation. One should note, however, that our work goes further by demonstrating how the efficacy of $\mathrm{NO}_{2}$ and $\mathrm{HCHO}$ observations varies according to photochemical regime. Similar to Elbern et al. $(2000,2007)$, we demonstrate the use of ozone in this regard. Our work offers an extension to Elbern et al. $(2000,2007)$ by considering the photochemical regime and by considering other observations simultaneously.

Note that the statements above regarding the need to constrain $\mathrm{NO}$ and VOC emissions under $\mathrm{NO}_{x^{-}}$and VOClimited conditions, respectively, are consistent with expectations since ozone is more sensitive to both sets of emission uncertainties under the respective conditions. Further, the use of ozone to constrain either $\mathrm{NO}_{x}$ or VOC emissions in either of the respective photochemical regimes is fully consistent with existing theory relating to ozone control strategies (Sillman, 1993) and our understanding of factors controlling ozone on regional and continental scales (Jacob et al., 1993). This was one motivation for us to explore this problem.

There is one further advantage to observations of ozone and $\mathrm{HCHO}$ made under VOC-limited conditions. Often, plumes of $\mathrm{NO}_{x}$-polluted and VOC-limited air can be exported from regions that are VOC limited into areas that are $\mathrm{NO}_{x}$ limited, and this can lead to significant temporal variability in the photochemical regime in the regions surrounding an urban centre. Therefore, observations of $\mathrm{HCHO}$ and ozone in addition to $\mathrm{NO}_{2}$ observations could help to understand such events and in turn reduce ozone prediction errors.

We have indirectly performed a sensitivity test to see if $\mathrm{CO}$ observations affect ozone a posteriori prediction errors. We can address their potential impact within the OCN scenario by examining the Jacobian matrix (see Fig. 4). This shows that ozone is relatively insensitive to perturbations in $\mathrm{CO}$ emissions and, therefore, also to a posteriori $\mathrm{CO}$ emission uncertainties. In fact, it appears that only the $\beta=5.0$ noise scenario has sufficiently large a posteriori $\mathrm{CO}$ emission error to cause significant a posteriori ozone prediction error (about $5 \mathrm{ppbv}$ ). The Jacobian predicts perturbations in $\mathrm{CO}$ as- 
sociated with such emission error to be over 700 ppbv. Such large changes in $\mathrm{CO}$ mixing ratios can occur in reality in urban areas from the influence of wildfires. For instance, $\mathrm{CO}$ mixing ratios were as high as $10 \mathrm{ppmv}$ during the summer of 2010 as a direct result of the rare and extreme fire events occurring in Russia that summer (Krol et al., 2013; Konovalov et al., 2011). Episodic perturbations of only $\sim 700 \mathrm{ppbv}$ are therefore more likely to result from the more frequent and less severe wildfire events that occur within Europe on an annual basis.

\subsection{Observation error}

We now make some broad conclusions regarding the observation uncertainties. Both the OCN and standard HCN scenarios achieve a posteriori ozone prediction errors of 2.4-6.1 and $1.9-6.3 \mathrm{ppbv}$, respectively, when absolute errors equivalent to $33 \%$ of the average over polluted regions were used. Even though the OCN and HCN scenarios compared favourably to one another in terms of their a posteriori ozone prediction errors, when we considered more realistic observational noise on the $\mathrm{HCHO}$ observations, the performance of the HCN scenario was degraded to $2.2-6.9 \mathrm{ppbv}$ ( $33 \%$ noise level). In comparison, for the same noise level, the $\mathrm{CN}$ scenario achieved ozone prediction errors of 2.5-8.4 ppbv. Only when the noise level was reduced to $25 \%$ were the OCN and HCN scenarios able to achieve ozone prediction errors of $5 \mathrm{ppbv}$ or less. At $10 \%$ noise, ozone prediction errors of less than $2.5 \mathrm{ppbv}$ were consistently attained for both $\mathrm{OCN}$ and HCN. This strongly points towards there being a good payoff in forecast accuracy with reducing observation error. Further work in a 3-D framework would be required in order to determine how these ozone forecast errors translate into the context of real air quality forecasting. For instance, it might be possible to calculate the probability of detection or false-alarm rate statistics in a similar way to the work carried out by Hache et al. (2014).

Connecting this to real instrument profiles and real observations, and how these might perform in a real assimilation system, is beyond the scope of this study. The furthest we can take this point is to note that the resulting prediction uncertainties for a particular observation noise scenario are optimistic and represent the lowest error that could be expected. This is because of reduced complexity in our model's representation of its spatial domain and its meteorology and because of the way we represented the errors in our observations, which in reality would be more complex.

\subsection{Temporal considerations}

Concerning the temporal sampling of observations, there is a strong sensitivity of ozone prediction error to observation removal in the daytime, particularly in the afternoon, and therefore observations made during the day present greater returns in terms of improved forecasting ability. The $\mathrm{NO}_{x}$ - limited regimes favour observations made throughout the day with increased observing density close to 15:00 LT The VOC-limited regimes favour a greater concentration of observations within the afternoon even up to 18:00 LT in the most VOC-limited cases. These differing results for the two different photochemical regimes are consistent with existing knowledge about photochemistry and $\mathrm{NO}_{x}$ lifetime. The main underlying factors controlling this are the changing time at which ozone peaks and the time of day that emissions occur that contribute to that peak. Under VOC-limited conditions ozone peaks later in the day due to the reduced ozone lifetime and the slower recovery of $\mathrm{HO}_{x}$ radicals (suppressed by $\mathrm{NO}_{x}$ ) that occurs after the night-time period. The $\mathrm{NO}_{x}$ limited scenarios also show a smaller peak in the morning. This smaller peak is present due to the observations of ozone and $\mathrm{NO}_{2}$ during the morning rush hour that better allow $\mathrm{NO}_{x}$ emissions to be constrained. The presence of the smaller peak also indicates that peak afternoon ozone concentrations are sensitive to the morning rush hour emissions of $\mathrm{NO}_{x}$; this is possible due to the longer ozone lifetime present under $\mathrm{NO}_{x}-$ limited conditions.

We demonstrate that the ozone prediction error is sensitive to the frequency of observation. We show that ozone prediction errors vary between negligible values and up to $12.5 \mathrm{ppbv}$ as the observing frequency varies between once per hour to once per day, respectively. The ozone prediction error is maximised within either the $\mathrm{NO}_{\mathrm{x}}$-limited or VOClimited regimes. We find very similar levels of ozone prediction error for the scenarios that observe once every hour and every $3 \mathrm{~h}$ (1.8-3.2 ppbv compared to $2.2-4.8 \mathrm{ppbv}$, respectively), and we also find that ozone prediction errors greater than 5 ppbv only emerge for observing scenarios using a frequency of $6 \mathrm{~h}$ or more. The fact that our forecasting system performs best using observations made at a frequency of $3 \mathrm{~h}$ or less highlights the temporal sampling advantage posed by the ground observation network relative to observing systems with lower observing frequency, i.e. a satellite in LEO configuration.

It is likely that there is an effect on ozone prediction error due to the interaction between observing frequency and observing time. Figure 10 implies that observing scenarios measuring at the same frequency could yield different prediction errors due to when they actually sampled during the diurnal cycle. However, in each test we made at a particular observing frequency, the observations were made at a fixed specific set of times, and so our work does not address this issue. We do think that this is relevant to evaluating different types of observing scenario, and we would therefore like to explore this problem in a future paper.

\subsection{Implications for emission inversion}

Aside from the relevance of these results to air quality forecasting and research in general, we believe these results are also relevant for emission and flux estimation via in- 
version methodologies. Our prototype framework is very similar to other work using 4D-variational data assimilation methodologies (Elbern et al., 2000, 2007; Henze et al., 2009; Stavrakou et al., 2009; Kopacz et al., 2010) and chemistry transport models that have focused on emission inversion. Much of the emission inversion performance shown in this study is driven by the photochemistry, and it is reasonable to suppose that some of our results are relevant to future work conducted using 4D-variational data assimilation in emission inversion studies. Note too that Kalman filter methods can also be used in this application and we should expect that the performance of this method will be similarly affected by photochemistry. From this premise, we recommend that emission inversion studies for $\mathrm{NO}_{x}$ utilise both observations of $\mathrm{NO}_{2}$ and ozone since ozone observations add information to the $x_{\mathrm{NO}}$ estimation under both strongly positively and negatively $\mathrm{NO}_{x}$-limited conditions and $\mathrm{NO}_{2}$ observations constrain emission parameter uncertainties the most under the more VOC-limited conditions. Thus, these two observations are complementary to each other. Likewise, for emission inversions of VOCs, we recommend observations of $\mathrm{HCHO}$ and ozone since $\mathrm{HCHO}$ observations can constrain VOC emission uncertainties under a wide variety of photochemical conditions and ozone can constrain VOC emission uncertainties under VOC-limited conditions.

Previous studies have shown that $\mathrm{NO}_{2}$ (Konovalov et al., 2006; Zhang et al., 2008; Müller and Stavrakou, 2005) and HCHO (Stavrakou et al., 2009; Millet et al., 2006, 2008; Palmer et al., 2003, 2006; Zhang et al., 2008) observations can constrain $\mathrm{NO}_{x}$ and VOC emissions, respectively. Although one could have inferred that combining ozone observations with either $\mathrm{NO}_{2}$ or $\mathrm{HCHO}$ observations would be beneficial, we have shown that it could be highly advantageous, which is consistent with Miyazaki et al. (2012).

It should be noted that the conclusions regarding VOC emission inversion are sensitive to our choice of representing VOC emission uncertainties with ethene. The success of the VOC emission inversion is significantly limited by solving for ethane instead of ethene emission uncertainties. This is due to the lack of impact on secondary chemical species such as HCHO. This is one reason why previous emission inversion modelling studies have focused on constraining reactive VOCs like isoprene (Millet et al., 2006, 2008; Palmer et al., 2003, 2006).

Concerning $\mathrm{CO}$, all of the observing scenarios $(\mathrm{CN}, \mathrm{OCN}$, and $\mathrm{HCN}$ ) performed equally well at constraining $\mathrm{CO}$ emission uncertainties since all these scenarios included observations of $\mathrm{CO}$. The Jacobian for $\mathrm{CO}$ with respect to $\mathrm{CO}$ emission perturbations shown in Fig. 4 clearly shows a strong sensitivity of $\mathrm{CO}$ to changes in its own emissions. On the other hand, Fig. 4 shows much lower sensitivity of $\mathrm{CO}$ to the emissions of NO or VOCs. These results are fully consistent with expectations due to the relatively low reactivity of $\mathrm{CO}$ and its potential to produce ozone on short timescales and of the lack of a strong chemical connection between $\mathrm{NO}_{x}$ levels and resulting $\mathrm{CO}$ concentrations. In the latter case, there is a link due to the way that $\mathrm{NO}_{x}$ can perturb $\mathrm{OH}$, but due to the relative unreactivity of $\mathrm{CO}$ this leads to only weak sensitivity in the Jacobian. Consistent with this, there have already been several studies that use observations of $\mathrm{CO}$ to constrain $\mathrm{CO}$ emissions (Müller and Stavrakou, 2005; Kopacz et al., 2010; Arellano et al., 2006).

In the supporting sensitivity analysis probing emission solution sensitivity to diurnal emission variability we demonstrate that emission inversions are potentially highly sensitive to the assumed variability in the emissions and that even perfect observations would lead to such errors. In our system such emission inversion errors would be hard to characterise in the absence of any information regarding the true state of the emissions variability. We recommend that such uncertainties should be considered and characterised in emissions inversion studies. Currently diurnal emission variabilities are determined in the process of building bottom-up emission inventories. Although our prototype assimilation system can only currently solve for time-independent scaling factors, it could be modified to solve for time-dependent scaling factors and the diurnal emissions variability. Future assimilation forecasting systems should also possess this ability to solve for time-dependent emission scaling factors. Observations that adequately capture the diurnal variability in pollutants will be essential to making this leap from time-independent solutions to time-dependent solutions.

\subsection{Implications for GEO and LEO satellites}

In the previous sections we have motivated the potential utility of surface or boundary layer ozone, $\mathrm{CO}, \mathrm{NO}_{2}$, and $\mathrm{HCHO}$ observations either in the context of improving ozone forecasting or for emission inversions. Ground station networks that implicitly sample boundary layer air are already in place across the American and European continents. However, only one of the current generation of LEO satellite instruments (MOPITT) possesses a reliable means of attaining unique instrument sensitivity to the boundary layer for these gases (Worden et al., 2013). If full advantage is to be taken of future GEO stationary satellite instruments' (GEOCAPE/TEMPO, GEMS, and Sentinel-4) simultaneous potential for excellent coverage and temporal sampling, with the aim of fully contributing to state of the art ozone air quality forecasting, then attaining sensitivity to the boundary layer is essential and should be a high-priority aim.

The heightened importance of observations made during the morning and mid- to late afternoon raises the question of whether making more targeted observations, for instance during the morning and evening rush hours, would be able to support ozone forecasting even further. There are various observing systems that would be able to provide this capability, such as several combined LEO missions or ground stations or a GEO mission with increased temporal sampling capability during those periods. Investigating these questions in 
the future would be of interest to us and the broader scientific community.

Our forecasting system is better able to improve the ozone prediction using observations made during the day as opposed to the night. In the context of satellites, and remembering that our idealised case ignores the effects of transport, this indicates that instruments capable of observing during the night, such as those observing in the TIR, do not offer a significant advantage over instruments restricted to making measurements during the daytime. Of course, if the effects of transported pollution were to be considered, such as the night-time mixing of ozone between the boundary layer and free troposphere, then making observations during the night could offer additional utility by improving the estimated contribution to the pollution made by this process. For instance, this could provide advance warning of the trajectory of a pollution plume. Therefore, a limitation of this work is that we are not able to explore such effects using a model with only idealised meteorology.

Our forecasting system (and the emission inversion) performs best using observations made at a frequency of $3 \mathrm{~h}$ or less. This highlights the temporal sampling advantage posed by satellites in a GEO configuration as opposed to those in LEO. Currently, the proposed observing frequencies for the future GEO missions (Lahoz et al., 2012) and the current ground monitoring network are at least $1 \mathrm{~h}$. LEO satellites, on the other hand, cannot attain high-frequency sampling without a large number of satellites being employed (Lahoz et al., 2012). In isolation, a single LEO satellite with a sampling frequency of between 1 and 16 days is perhaps inadequate for the purpose of constraining precursor emissions on the regional scale or for supporting air quality forecasting. Another consideration is that observing frequencies of $3 \mathrm{~h}$ or more might not be adequate for studying the diurnal cycle of pollutants and for forecasting systems that use 3D-var, for instance, to update ozone concentrations. Note that the nature of our framework for performing these tests (i.e. a box model using only idealised meteorology) places limitations on our conclusions such that the performance of the higherfrequency observing scenarios ( $3 \mathrm{~h}$ or less) may be too optimistic. Thus, observing at $3 \mathrm{~h}$ may be insufficient to constrain ozone precursor emissions.

Acknowledgements. The authors thank CNRM-GAME for paying the publication fees. P. D. Hamer thanks ORAU and the NPP program for funding and support, D. Millet and D. Jacob for helpful discussion and comments, and A. M. Aghedo for help and formatting tips. D. K. Henze is supported by NASA Applied Science Program. The research was carried out at the Jet Propulsion Laboratory, California Institute of Technology, under a contract with the National Aeronautics and Space Administration. Government sponsorship acknowledged. This paper is dedicated to the memory of C. J. Hamer.

Edited by: W. Lahoz

\section{References}

Arellano, A., Kasibhatla, P., Giglio, L., van der Werf, G., Randerson, J., and Collatz, G.: Time-dependent inversion estimates of global biomass-burning CO emissions using Measurement of Pollution in the Troposphere (MOPITT) measurements, J. Geophys. Res.-Atmos., 111, D09303, doi:10.1029/2005JD006613, 2006.

Blanchard, C. and Fairley, D.: Spatial mapping of VOC and $\mathrm{NO}_{x}-$ limitation of ozone formation in central California, Atmos. Environ., 35, 3861-3873, doi:10.1016/S1352-2310(01)00153-4, 2001.

Blanchard, C. and Tanenbaum, S.: Differences between weekday and weekend air pollutant levels in southern California, J. Air Waste Manage., 53, 816-828, 2003.

Bowman, K. W., Jones, D. B. A., Logan, J. A., Worden, H., Boersma, F., Chang, R., Kulawik, S., Osterman, G., Hamer, P., and Worden, J.: The zonal structure of tropical $\mathrm{O}_{3}$ and $\mathrm{CO}$ as observed by the Tropospheric Emission Spectrometer in November 2004 - Part 2: Impact of surface emissions on $\mathrm{O}_{3}$ and its precursors, Atmos. Chem. Phys., 9, 3563-3582, doi:10.5194/acp-93563-2009, 2009.

Chai, T., Carmichael, G. R., Tang, Y., Sandu, A., Hardesty, M., Pilewskie, P., Whitlow, S., Browell, E. V., Avery, M. A., Nedelec, P., Merrill, J. T., Thompson, A. M., and Williams, E.: Four-dimensional data assimilation experiments with International Consortium for Atmospheric Research on Transport and Transformation ozone measurements, J. Geophys. Res.-Atmos., 112, D12S15, doi:10.1029/2006JD007763, 2007.

Cuesta, J., Eremenko, M., Liu, X., Dufour, G., Cai, Z., Höpfner, M., von Clarmann, T., Sellitto, P., Foret, G., Gaubert, B., Beekmann, M., Orphal, J., Chance, K., Spurr, R., and Flaud, J.-M.: Satellite observation of lowermost tropospheric ozone by multispectral synergism of IASI thermal infrared and GOME-2 ultraviolet measurements over Europe, Atmos. Chem. Phys., 13, 9675-9693, doi:10.5194/acp-13-9675-2013, 2013.

Dabberdt, W. F., Carroll, M., Baumgardner, D., Carmichael, G., Cohen, R., Dye, T., Ellis, J., Grell, G., Grimmond, S., Hanna, S., Irwin, J., Lamb, B., Madronich, S., McQueen, J., Meagher, J., Odman, T., Pleim, J., Schmid, H., and Westphal, D.: Meteorological research needs for improved air quality forecasting - Report of the 11th prospectus development team of the US Weather Research Program, B. Am. Meteorol. Soc., 85, 563586, doi:10.1175/BAMS-85-4-563, 2004.

Dabberdt, W. F., Carroll, M. A., Appleby, W., Baumgardner, D., Carmichael, G., Davidson, P., Doran, J. C., Dye, T. S., Grimmond, S., Middleton, P., Neff, W., and Zhang, Y.: USWRP Workshop on Air Quality Forecasting, B. Am. Meteorol. Soc., 87, 215-221, 2006.

Daescu, D., Sandu, A., and Carmichael, G.: Direct and adjoint sensitivity analysis of chemical kinetic systems with KPP: II - Numerical validation and applications, Atmos. Environ., 37, 50975114, doi:10.1016/j.atmosenv.2003.08.020, 2003.

Damian, V., Sandu, A., Damian, M., Potra, F., and Carmichael, G.: The kinetic preprocessor KPP - a software environment for solving chemical kinetics, Comput. Chem. Eng., 26, 1567-1579, 2002.

Dufour, G., Eremenko, M., Orphal, J., and Flaud, J.-M.: IASI observations of seasonal and day-to-day variations of tropospheric ozone over three highly populated areas of China: Bei- 
jing, Shanghai, and Hong Kong, Atmos. Chem. Phys., 10, 37873801, doi:10.5194/acp-10-3787-2010, 2010.

Duncan, B. N., Yoshida, Y., Olson, J. R., Sillman, S., Martin, R. V., Lamsal, L., Hu, Y., Pickering, K. E., Retscher, C., Allen, D. J., and Crawford, J. H.: Application of OMI observations to a space-based indicator of $\mathrm{NO}_{x}$ and VOC controls on surface ozone formation, Atmos. Environ., 44, 2213-2223, doi:10.1016/j.atmosenv.2010.03.010, 2010.

Elbern, H., Schmidt, H., Talagrand, O., and Ebel, A.: 4Dvariational data assimilation with an adjoint air quality model for emission analysis, Environ. Model. Softw., 15, 539-548, doi:10.1016/S1364-8152(00)00049-9, 2000.

Elbern, H., Strunk, A., Schmidt, H., and Talagrand, O.: Emission rate and chemical state estimation by 4-dimensional variational inversion, Atmos. Chem. Phys., 7, 3749-3769, doi:10.5194/acp7-3749-2007, 2007.

Eller, P., Singh, K., Sandu, A., Bowman, K., Henze, D. K., and Lee, M.: Implementation and evaluation of an array of chemical solvers in the Global Chemical Transport Model GEOSChem, Geosci. Model Dev., 2, 89-96, doi:10.5194/gmd-2-892009, 2009.

Finlayson-Pitts, B. and Pitts, J.: Tropospheric air pollution: Ozone, airborne toxics, polycyclic aromatic hydrocarbons, and particles, Science, 276, 1045-1052, doi:10.1126/science.276.5315.1045, 1997.

Fishman, J., Creilson, J. K., Parker, P. A., Ainsworth, E. A., Vining, G. G., Szarka, J., Booker, F. L., and Xu, X.: An investigation of widespread ozone damage to the soybean crop in the upper Midwest determined from ground-based and satellite measurements, Atmos. Environ., 44, 2248-2256, doi:10.1016/j.atmosenv.2010.01.015, 2010.

Fu, D., Worden, J. R., Liu, X., Kulawik, S. S., Bowman, K. W., and Natraj, V.: Characterization of ozone profiles derived from Aura TES and OMI radiances, Atmos. Chem. Phys., 13, 3445-3462, doi:10.5194/acp-13-3445-2013, 2013.

Fumagalli, I., Gimeno, B., Velissariou, D., De Temmerman, L., and Mills, G.: Evidence of ozone-induced adverse effects on crops in the Mediterranean region, Atmos. Environ., 35, 2583-2587, 2001.

Gardner, M. and Dorling, S.: Statistical surface ozone models: an improved methodology to account for non-linear behaviour, Atmos. Environ., 34, 21-34, 2000.

Grell, G. A., Peckham, S. E., Schmitz, R., McKeen, S. A., Frost, G., Skamarock, W. C., and Eder, B.: Fully coupled "online" chemistry within the WRF model, Atmos. Environ., 39, 6957-6975, doi:10.1016/j.atmosenv.2005.04.027, 2005.

Hache, E., Attié, J.-L., Tourneur, C., Ricaud, P., Coret, L., Lahoz, W. A., El Amraoui, L., Josse, B., Hamer, P., Warner, J., Liu, X., Chance, K., Höpfner, M., Spurr, R., Natraj, V., Kulawik, S., Eldering, A., and Orphal, J.: The added value of a visible channel to a geostationary thermal infrared instrument to monitor ozone for air quality, Atmos. Meas. Tech., 7, 2185-2201, doi:10.5194/amt7-2185-2014, 2014.

Hakami, A., Henze, D. K., Seinfeld, J. H., Singh, K., Sandu, A., Kim, S., Byun, D., and Li, Q.: The adjoint of CMAQ, Environ. Sci. Technol., 41, 7807-7817, 2007.

Henze, D. K., Seinfeld, J. H., and Shindell, D. T.: Inverse modeling and mapping US air quality influences of inorganic $\mathrm{PM}_{2.5}$ precursor emissions using the adjoint of GEOS-Chem, At- mos. Chem. Phys., 9, 5877-5903, doi:10.5194/acp-9-5877-2009, 2009.

IPCC: Inter-Governmental Panel on Climate Change Fourth Assessment Report Working Group 1 Report "The Physical Basis", edited by: Solomon, S., Qin, D., Manning, M., Chen, Z., Marquis, M., Averyt, K. B., Tignor, M., and Miller, H. L., Vol. 2, 150-152 Cambridge University Press, Cambridge, United Kingdom and New York, NY, USA, 2007.

Jacob, D., Logan, J., Gardner, G., Yevich, R., Spivakovsky, C., Wofsy, S., Sillman, S., and Prather, M.: Factors regulating ozone over the United-States and its export to the global atmosphere, J. Geophys. Res.-Atmos., 98, 14817-14826, doi:10.1029/98JD01224, 1993.

Jenkin, M., Saunders, S., and Pilling, M.: The tropospheric degradation of volatile organic compounds: A protocol for mechanism development, Atmos. Environ., 31, 81-104, 1997.

Jones, D. B. A., Bowman, K. W., Logan, J. A., Heald, C. L., Liu, J., Luo, M., Worden, J., and Drummond, J.: The zonal structure of tropical $\mathrm{O}_{3}$ and $\mathrm{CO}$ as observed by the Tropospheric Emission Spectrometer in November 2004 - Part 1: Inverse modeling of CO emissions, Atmos. Chem. Phys., 9, 3547-3562, doi:10.5194/acp-9-3547-2009, 2009.

Kang, D., Mathur, R., and Rao, S. T.: Real-time bias-adjusted $\mathrm{O}_{3}$ and $\mathrm{PM}_{2.5}$ air quality index forecasts and their performance evaluations over the continental United States, Atmos. Environ., 44, 2203-2212, doi:10.1016/j.atmosenv.2010.03.017, 2010.

Konovalov, I. B., Beekmann, M., Richter, A., and Burrows, J. P.: Inverse modelling of the spatial distribution of $\mathrm{NO}_{x}$ emissions on a continental scale using satellite data, Atmos. Chem. Phys., 6, 1747-1770, doi:10.5194/acp-6-1747-2006, 2006.

Konovalov, I. B., Beekmann, M., Kuznetsova, I. N., Yurova, A., and Zvyagintsev, A. M.: Atmospheric impacts of the 2010 Russian wildfires: integrating modelling and measurements of an extreme air pollution episode in the Moscow region, Atmos. Chem. Phys., 11, 10031-10056, doi:10.5194/acp-11-10031-2011, 2011.

Kopacz, M., Jacob, D. J., Fisher, J. A., Logan, J. A., Zhang, L., Megretskaia, I. A., Yantosca, R. M., Singh, K., Henze, D. K., Burrows, J. P., Buchwitz, M., Khlystova, I., McMillan, W. W., Gille, J. C., Edwards, D. P., Eldering, A., Thouret, V., and Nedelec, P.: Global estimates of CO sources with high resolution by adjoint inversion of multiple satellite datasets (MOPITT, AIRS, SCIAMACHY, TES), Atmos. Chem. Phys., 10, 855-876, doi:10.5194/acp-10-855-2010, 2010.

Krol, M., Peters, W., Hooghiemstra, P., George, M., Clerbaux, C., Hurtmans, D., McInerney, D., Sedano, F., Bergamaschi, P., El Hajj, M., Kaiser, J. W., Fisher, D., Yershov, V., and Muller, J.-P.: How much CO was emitted by the 2010 fires around Moscow?, Atmos. Chem. Phys., 13, 4737-4747, doi:10.5194/acp-13-47372013, 2013.

Kurokawa, J.-I., Yumimoto, K., Uno, I., and Ohara, T.: Adjoint inverse modeling of $\mathrm{NO}_{x}$ emissions over eastern China using satellite observations of $\mathrm{NO}_{2}$ vertical column densities, Atmos. Environ., 43, 1878-1887, doi:10.1016/j.atmosenv.2008.12.030, 2009.

Lahoz, W. A., Peuch, V. H., Orphal, J., Attie, J. L., Chance, K., Liu, X., Edwards, D., Elbern, H., Flaud, J. M., Claeyman, M., and El Amraoui, L.: Monitoring air quality from space: The Case for the Geostationary Platform, B. Am. Meteorol. Soc., 93, 221-233, doi:10.1175/BAMS-D-11-00045.1, 2012. 
Landgraf, J. and Hasekamp, O. P.: Retrieval of tropospheric ozone: The synergistic use of thermal infrared emission and ultraviolet reflectivity measurements from space, J. Geophys. Res.-Atmos., 112, doi:10.1029/2006JD008097, 2007.

Lee, S., Hong, Y., Song, C., Lee, M., Ryoo, S., Kim, J., Yong, S., Bhartia, P. K., Park, R., Woo, J., Kim, Y. J., Song, C. H., Kim, J. H., Lee, K., Ho, C., Park, S. K., Lee, Y., Lee, J., Kim, M., Eom, Y., and Hong, J.: Geostationary Environment Monitoring Spectrometer(GEMS) onboard MP-GEOSAT (Multi Purpose Geostationary Satellite) over Asia-Pacific region, Am. Geophys. Un., Vol. 1, p. 251, 2009.

Marécal, V., Peuch, V.-H., Andersson, C., Andersson, S., Arteta, J., Beekmann, M., Benedictow, A., Bergström, R., Bessagnet, B., Cansado, A., Chéroux, F., Colette, A., Coman, A., Curier, R. L., Denier van der Gon, H. A. C., Drouin, A., Elbern, H., Emili, E., Engelen, R. J., Eskes, H. J., Foret, G., Friese, E., Gauss, M., Giannaros, C., Guth, J., Joly, M., Jaumouillé, E., Josse, B., Kadygrov, N., Kaiser, J. W., Krajsek, K., Kuenen, J., Kumar, U., Liora, N., Lopez, E., Malherbe, L., Martinez, I., Melas, D., Meleux, F., Menut, L., Moinat, P., Morales, T., Parmentier, J., Piacentini, A., Plu, M., Poupkou, A., Queguiner, S., Robertson, L., Rouïl, L., Schaap, M., Segers, A., Sofiev, M., Tarasson, L., Thomas, M., Timmermans, R., Valdebenito, Á., van Velthoven, P., van Versendaal, R., Vira, J., and Ung, A.: A regional air quality forecasting system over Europe: the MACC-II daily ensemble production, Geosci. Model Dev., 8, 2777-2813, doi:10.5194/gmd8-2777-2015, 2015.

Martin, R. V.: Satellite remote sensing of surface air quality, Atmos. Environ., 42, 7823-7843, doi:10.1016/j.atmosenv.2008.07.018, 2008.

Millet, D. B., Jacob, D. J., Turquety, S., Hudman, R. C., Wu, S., Fried, A., Walega, J., Heikes, B. G., Blake, D. R., Singh, H. B., Anderson, B. E., and Clarke, A. D.: Formaldehyde distribution over North America: Implications for satellite retrievals of formaldehyde columns and isoprene emission, J. Geophys. Res.Atmos., 111, D24S02, doi:10.1029/2005JD006853, 2006.

Millet, D. B., Jacob, D. J., Boersma, K. F., Fu, T.-M., Kurosu, T. P., Chance, K., Heald, C. L., and Guenther, A.: Spatial distribution of isoprene emissions from North America derived from formaldehyde column measurements by the OMI satellite sensor, J. Geophys. Res.-Atmos., 113, D02307, doi:10.1029/2007JD008950, 2008.

Miyazaki, K., Eskes, H. J., Sudo, K., Takigawa, M., van Weele, M., and Boersma, K. F.: Simultaneous assimilation of satellite $\mathrm{NO}_{2}$, $\mathrm{O}_{3}$, $\mathrm{CO}$, and $\mathrm{HNO} 3$ data for the analysis of tropospheric chemical composition and emissions, Atmos. Chem. Phys., 12, 95459579, doi:10.5194/acp-12-9545-2012, 2012.

Müller, J.-F. and Stavrakou, T.: Inversion of $\mathrm{CO}$ and $\mathrm{NO}_{x}$ emissions using the adjoint of the IMAGES model, Atmos. Chem. Phys., 5, 1157-1186, doi:10.5194/acp-5-1157-2005, 2005.

Murphy, J., Delucchi, M., McCubbin, D., and Kim, H.: The cost of crop damage caused by ozone air pollution from motor vehicles, J. Environ. Manage., 55, 273-289, 1999.

Mustafa, M.: Biochemical basis of ozone toxicity, Free Radical Bio. Med., 9, 245-265, 1990.

Nali, C., Pucciariello, C., and Lorenzini, G.: Ozone distribution in central Italy and its effect on crop productivity, Agr. Ecosys. Environ., 90, 277-289, 2002.
Otte, T., Pouliot, G., Pleim, J., Young, J., Schere, K., Wong, D., Lee, P., Tsidulko, M., McQueen, J., Davidson, P., Mathur, R., Chuang, H., DiMego, G., and Seaman, N.: Linking the Eta Model with the Community Multiscale Air Quality (CMAQ) modeling system to build a national air quality forecasting system, Weather Forecast., 20, 367-384, 2005.

Palmer, P., Jacob, D., Fiore, A., Martin, R., Chance, K., and Kurosu, T.: Mapping isoprene emissions over North America using formaldehyde column observations from space, J. Geophys. Res.-Atmos., 108, 4180, doi:10.1029/2002JD002153, 2003.

Palmer, P. I., Abbot, D. S., Fu, T.-M., Jacob, D. J., Chance, K., Kurosu, T. P., Guenther, A., Wiedinmyer, C., Stanton, J. C., Pilling, M. J., Pressley, S. N., Lamb, B., and Sumner, A. L.: Quantifying the seasonal and interannual variability of North American isoprene emissions using satellite observations of the formaldehyde column, J. Geophys. Res.-Atmos., 111, D12315, doi:10.1029/2005JD006689, 2006.

Parrington, M., Jones, D. B. A., Bowman, K. W., Thompson, A. M., Tarasick, D. W., Merrill, J., Oltmans, S. J., Leblanc, T., Witte, J. C., and Millet, D. B.: Impact of the assimilation of ozone from the Tropospheric Emission Spectrometer on surface ozone across North America, Geophys. Res. Lett., 36, L04802, doi:10.1029/2008GL036935, 2009.

Pierce, R. B., Schaack, T., Al-Saadi, J. A., Fairlie, T. D., Kittaka, C., Lingenfelser, G., Natarajan, M., Olson, J., Soja, A., Zapotocny, T., Lenzen, A., Stobie, J., Johnson, D., Avery, M. A., Sachse, G. W., Thompson, A., Cohen, R., Dibb, J. E., Crawford, J., Rault, D., Martin, R., Szykman, J., and Fishman, J.: Chemical data assimilation estimates of continental US ozone and nitrogen budgets during the Intercontinental Chemical Transport Experiment-North America, J. Geophys. Res.-Atmos., 112, D12S21, doi:10.1029/2006JD007722, 2007.

Pryor, W.: How Far Does Ozone Penetrate Into The Pulmonary Air Tissue Boundary Before It Reacts, Free Radical Bio. Med., 12, 83-88, 1992.

Rodgers, C. D.: Inverse Methods for Atmospheric Sounding - Theory and Practice, World Scientific, Singapore, Vol. 2, 65-79, 2000.

Sandu, A., Daescu, D., and Carmichael, G.: Direct and adjoint sensitivity analysis of chemical kinetic systems with KPP: Part I - theory and software tools, Atmos. Environ., 37, 5083-5096, doi:10.1016/j.atmosenv.2003.08.019, 2003a.

Sandu, A., Daescu, D., and Carmichael, G.: Direct and adjoint sensitivity analysis of chemical kinetic systems with KPP: Part I - theory and software tools, Atmos. Environ., 37, 5083-5096, doi:10.1016/j.atmosenv.2003.08.019, 2003b.

Sillman, S.: Tropospheric ozone - the debate over control strategies, Annu. Rev. Energ. Environ., 18, 31-56, doi:10.1146/annurev.energy.18.1.31, 1993.

Stavrakou, T., Müller, J.-F., De Smedt, I., Van Roozendael, M., van der Werf, G. R., Giglio, L., and Guenther, A.: Global emissions of non-methane hydrocarbons deduced from SCIAMACHY formaldehyde columns through 2003-2006, Atmos. Chem. Phys., 9, 3663-3679, doi:10.5194/acp-9-3663-2009, 2009.

Strunk, A., Ebel, A., Elbern, H., Friese, E., Goris, N., and Nieradzik, L. P.: Four-Dimensional variational assimilation of atmospheric chemical data-application to regional modelling of air quality, in: Large-Scale Scientific Computing, 214-222, Springer, New York, 2010. 
Tawfik, A. B., Stoeckli, R., Goldstein, A., Pressley, S., and Steiner, A. L.: Quantifying the contribution of environmental factors to isoprene flux interannual variability, Atmos. Environ., 54, 216224, doi:10.1016/j.atmosenv.2012.02.018, 2012.

Tingey, D., Manning, M., Grothaus, L., and Burns, W.: Influence of light and temperature on isoprene emission rates from LIVE OAK, Physiol. Plantarum, 47, 112-118, doi:10.1111/j.13993054.1979.tb03200.x, 1979.

Trainer, M., Williams, E., Parrish, D., Buhr, M., Allwine, E., Westberg, H., Fehsenfeld, F., and Liu, S.: Models and observations of the impact of natural hydrocarbons on rural ozone, Nature, 329, 705-707, doi:10.1038/329705a0, 1987.

Valente, R., Imhoff, R., Tanner, R., Meagher, J., Daum, P., Hardesty, R., Banta, R., Alvarez, R., McNider, R., and Gillani, N.: Ozone production during an urban air stagnation episode over Nashville, Tennessee, J. Geophys. Res.-Atmos., 103, 22555-22568, 1998.

Van Dingenen, R., Dentener, F. J., Raes, F., Krol, M. C., Emberson, L., and Cofala, J.: The global impact of ozone on agricultural crop yields under current and future air quality legislation, Atmos. Environ., 43, 604-618, doi:10.1016/j.atmosenv.2008.10.033, 2009.

WHO: Review of evidence on health aspects of air pollution, Tech. rep., WHO (World Health Organization), 2013.

Worden, H. M., Deeter, M. N., Edwards, D. P., Gille, J. C., Drummond, J. R., and Nedelec, P.: Observations of nearsurface carbon monoxide from space using MOPITT multispectral retrievals, J. Geophys. Res.-Atmos., 115, D18314, doi:10.1029/2010JD014242, 2010.

Worden, H. M., Edwards, D. P., Deeter, M. N., Fu, D., Kulawik, S. S., Worden, J. R., and Arellano, A.: Averaging kernel prediction from atmospheric and surface state parameters based on multiple regression for nadir-viewing satellite measurements of carbon monoxide and ozone, Atmos. Meas. Tech., 6, 1633-1646, doi:10.5194/amt-6-1633-2013, 2013.
Worden, J., Liu, X., Bowman, K., Chance, K., Beer, R., Eldering, A., Gunson, M., and Worden, H.: Improved tropospheric ozone profile retrievals using OMI and TES radiances, Geophys. Res. Lett., 34, L01809, doi:10.1029/2006GL027806, 2007.

Yi, J. and Prybutok, V.: A neural network model forecasting for prediction of daily maximum ozone concentration in an industrialized urban area, Environ. Pollut., 92, 349-357, 1996.

Zhang, L., Constantinescu, E. M., Sandu, A., Tang, Y., Chai, T., Carmichael, G. R., Byun, D., and Olaguer, E.: An adjoint sensitivity analysis and 4D-Var data assimilation study of Texas air quality, Atmos. Environ., 42, 5787-5804, doi:10.1016/j.atmosenv.2008.03.048, 2008.

Zhang, Y., Bocquet, M., Mallet, V., Seigneur, C., and Baklanov, A.: Real-time air quality forecasting, part II: State of the science, current research needs, and future prospects, Atmos. Environ., 60, 656-676, 2012.

Zhu, C., Byrd, R., Lu, P., and Nocedal, J.: Algorithm 778: L-BFGSB: Fortran subroutines for large-scale bound-constrained optimization, ACM T. Math. Softw., 23, 550-560, 1997.

Zoogman, P., Jacob, D. J., Chance, K., Zhang, L., Le Sager, P., Fiore, A. M., Eldering, A., Liu, X., Natraj, V., and Kulawik, S. S.: Ozone air quality measurement requirements for a geostationary satellite mission, Atmos. Environ., 45, 7143-7150, doi:10.1016/j.atmosenv.2011.05.058, 2011.

Zoogman, P., Jacob, D. J., Chance, K., Liu, X., Lin, M., Fiore, A., and Travis, K.: Monitoring high-ozone events in the US Intermountain West using TEMPO geostationary satellite observations, Atmos. Chem. Phys., 14, 6261-6271, doi:10.5194/acp-146261-2014, 2014. 